\title{
NF-kB p50 activation associated with immune dysregulation confers poorer survival for diffuse large B-cell lymphoma patients with wild-type p53
}

Qingqing Cai ${ }^{1,2,9}$, Meifeng Tu ${ }^{3,9}$, Zijun Y Xu-Monette ${ }^{2,9}$, Ruifang Sun ${ }^{2}$, Ganiraju C Manyam ${ }^{4}$, Xiaolu Xu ${ }^{1}$, Alexander Tzankov ${ }^{5}$, Eric D Hsi ${ }^{6}$, Michael B Møller ${ }^{7}$, L Jeffrey Medeiros ${ }^{2}$, Chi Young $\mathrm{Ok}^{2}$ and Ken H Young ${ }^{2,8}$

${ }^{1}$ Department of Medical Oncology, Sun Yat-sen University Cancer Center, State Key Laboratory of Oncology in South China, Collaborative Innovation Center of Cancer Medicine, Guangzhou, China; ${ }^{2}$ Department of Hematopathology, The University of Texas MD Anderson Cancer Center, Houston, TX, USA; ${ }^{3}$ Key laboratory of Carcinogenesis and Translational Research (Ministry of Education), Department of Lymphoma, Peking University Cancer Hospital \& Institute, Beijing, China; ${ }^{4}$ Department of Bioinformatics and Computational Biology, The University of Texas MD Anderson Cancer Center, Houston, TX, USA; ${ }^{5}$ Department of Pathology, University Hospital, Basel, Switzerland; ${ }^{6}$ Department of Pathology, Cleveland Clinic, Cleveland, OH, USA; ${ }^{7}$ Department of Pathology, Odense University Hospital, Odense, Denmark and ${ }^{8}$ The University of Texas School of Medicine, Graduate School of Biomedical Sciences, Houston, TX, USA

Dysregulated NF-KB signaling is critical for lymphomagenesis, however, the expression and clinical relevance of NF-KB subunit p50 in diffuse large B-cell lymphoma have not been evaluated. In this study, we analyzed the prognostic significance and gene expression signatures of p50 nuclear expression as a surrogate for p50 activation in $\mathbf{4 6 5}$ patients with de novo diffuse large B-cell lymphoma. We found that $\mathrm{p}^{+} 0^{+}$nuclear expression, observed in $34.6 \%$ of diffuse large B-cell lymphoma, predominantly composed of activated B-cell-like subtype, was an independent adverse prognostic factor in patients with activated B-cell-like diffuse large B-cell lymphoma. It was also an adverse prognostic factor in patients with wild-type TP53 independent of the activated B-cell-like and germinal center B-cell-like subtypes, even though p50 activation correlated with significantly lower levels of Myc, PI3K, phospho-AKT, and CXCR4 expression and less frequent BCL2 translocations. In contrast, in germinal center B-cell-like diffuse large B-cell lymphoma patients with TP53 mutations, p50 $^{+}$nuclear expression correlated with significantly better clinical outcomes, and decreased p53, Bcl-2, and Myc expression. Gene expression profiling revealed multiple signaling pathways potentially upstream the p50 activation through either canonical or noncanonical NF-KB pathways, and suggested that immune suppression, including that by the immune checkpoint TIM-3 and that through leukocyte immunoglobulin-like receptors, but not antiapoptosis and proliferation, may underlie the observed poorer survival rates associated with $\mathrm{p}^{+} 0^{+}$nuclear expression in diffuse large B-cell lymphoma. In conclusion, these data show that p50 is important as a unique mechanism of R-CHOP-resistance in activated B-cell-like diffuse large B-cell lymphoma and in patients without TP53 mutations. The results also provide insights into the regulation and function of p50 in diffuse large B-cell lymphoma and its cross talk with the p53 pathway with important therapeutic implications.

Modern Pathology (2017) 30, 854-876; doi:10.1038/modpathol.2017.5; published online 10 March 2017

Nuclear factor-kappa-B (NF- $\kappa \mathrm{B})$ is a well-known group of transcription factors that regulate cellular functions, including proliferation, apoptosis,

Correspondence: Dr KH Young, MD, PhD, Department of Hematopathology, The University of Texas MD Anderson Cancer Center, 1515 Holcombe Boulevard, Houston, TX 77030, USA.

E-mail: khyoung@mdanderson.org

${ }^{9}$ These authors contributed equally to this work

Received 30 September 2016; revised 29 December 2016; accepted 29 December 2016; published online 10 March 2017 angiogenesis, immune response, cell adhesion, and differentiation. The NF- $\kappa \mathrm{B}$ pathway is also involved in lymphomagenesis. ${ }^{1,2}$ In mammals, the NF- $\kappa \mathrm{B}$ family of proteins has five members: NF- $\kappa$ B1 (p50/ p105), NF- $\kappa$ B2 (p52/p100), RelA (p65), RelB, and $\mathrm{c}-$ Rel. Nearly all NF- $\kappa \mathrm{B}$ proteins can form homodimers and heterodimers, which can bind to DNA target sites ( $\mathrm{\kappa B}$ sites) and influence gene expression. p65/p50 is the most common heterodimer and is inactivated by the inhibitor of NF- $\kappa \mathrm{B}(\mathrm{I} \kappa \mathrm{B})$ in the 
cytosol. ${ }^{3}$ The I $\kappa$ B kinase (IKK) complex has a central role in $\mathrm{NF}-\kappa \mathrm{B}$ pathway activation by mediating the initial phosphorylation of $\mathrm{I} \kappa \mathrm{B}$ proteins. ${ }^{4}$ Aberrant activation of NF- $\kappa \mathrm{B}$ proteins through either the canonical pathway, which activates p50/p65 and p50/c-Rel dimers, or the noncanonical pathway, which activates p52/RelB dimers, has been associated with tumor cell survival and proliferation in diffuse large B-cell lymphoma. ${ }^{5}$

Among the NF- $\kappa \mathrm{B}$ family members, p50 is derived from a precursor molecule, p105, which can act as an $\mathrm{I} \kappa \mathrm{B}$ protein. $\mathrm{p} 105$ processing by proteasomes through phosphorylation and ubiqutination results in C-terminal degradation and a mature p50 transcription factor. Under $\mathrm{NF}-\kappa \mathrm{B}$ activating stimuli, p50 dimers translocate into the nucleus and execute transcriptional activities. ${ }^{6,7}$ p50 can function as a transcriptional activator only by forming a heterodimer with p65, RelB, or c-Rel; ${ }^{8}$ p50 homodimers and p50/p52 heterodimers cannot act as transcription factors to activate downstream NF- $\kappa \mathrm{B}$ gene expression, but they can do so after forming a complex with Bcl-3, a member of the I $\kappa \mathrm{B}$ family. ${ }^{7,9}$ The complex biological functions of p50 in the regulation of protein expression is therefore much less well understood than that of the other subunits of the NF- $\kappa \mathrm{B}$ family. Overexpressed p50 in malignant tumors likely contributes to pathogenesis. It has been reported that the NF- $\kappa$ B1 polymorphism rs4648068 is associated with cell proliferation and motility in gastric cancer. ${ }^{10}$ Similarly, a study of patients with acute myeloid leukemia showed that the RelA/p50 and p50/p50 complexes of the canonical NF- $\kappa \mathrm{B}$ pathway are constitutively active in leukemic cells. ${ }^{11}$

However, NF- $\kappa \mathrm{B}$ signaling in tumor development also depends on p53 status. ${ }^{12}$ p53, encoded by the TP53 gene, is a tumor-suppressor protein that has an essential role in preventing the development of cancer. p53 acts as a transcription factor in the regulation of several important genes involved in cell cycle control, DNA repair, and apoptosis. ${ }^{13}$ The cross talk between NF- $\kappa$ B proteins and p53 has been examined in several recent studies. Relative levels of p53 and NF- $\kappa$ B affect the capability of each protein to regulate gene expression. ${ }^{14}$ Also, p53 can directly and negatively regulate $\mathrm{NF}-\kappa \mathrm{B}$ activation, ${ }^{15,16}$ whereas p53 mutants can cooperate with $\mathrm{NF}-\kappa \mathrm{B}$ to promote tumor invasion and metastasis. ${ }^{17}$ Conversely, NF- $\kappa \mathrm{B}$ antagonizes p53 activation and apoptosis, but can enhance p53 stability and activities in some circumstances. ${ }^{18}$ One group reported that p50 upregulates PHLPP1 (a AKT phosphatase)-targeting miR-190, thereby promoting p53 expression and apoptosis as a result of AKT/S6 ribosomal protein activation and enhanced protein translation. ${ }^{19}$

Diffuse large B-cell lymphoma is an aggressive type of non-Hodgkin lymphoma that can be classified by gene expression profiling into germinal center B-cell-like and activated B-cell-like types. Activated B-cell-like diffuse large B-cell lymphoma is distinguished from germinal center B-cell-like diffuse large B-cell lymphoma by preferential activation of the canonical NF- $\kappa \mathrm{B}$ pathway, in particular the p50/p65 and p50/c-Rel dimers. ${ }^{20,21}$ Therapeutic agents targeting the NF- $\kappa \mathrm{B}$ pathway are currently in clinical trials. Research regarding the role of specific $\mathrm{NF}-\kappa \mathrm{B}$ subunits in diffuse large B-cell lymphoma is urgently needed. ${ }^{21}$ However, the regulation, function, and clinical relevance of $\mathrm{p} 50 / \mathrm{NF}-\kappa \mathrm{B}$ activation in diffuse large B-cell lymphoma are not well understood. The relationship between p50 and p53 is also a topic of heated discussion with potential therapeutic implications.

In this study, we assessed p50 nuclear expression in diffuse large B-cell lymphoma $(n=465)$ and evaluated the impact of p50 expression on patient survival in the absence and presence of TP53 mutations. We also examined for the relationships and cross talk between p50 and p53 and other oncogenic pathways, as well as ${\mathrm{p} 50^{+}}^{+}$gene expression signatures to understand the potential underlying mechanisms.

\section{Materials and methods}

\section{Patients}

This study included 465 patients with de novo diffuse large B-cell lymphoma treated with standard immunochemotherapy consisting of rituximab plus cyclophosphamide, hydroxydaunomycin (doxorubicin), Oncovin (vincristine), and prednisone (R-CHOP) as part of the International diffuse large B-cell lymphoma R-CHOP Consortium Program Study. The diagnosis, review process, and cell-oforigin classification according to gene expression profiling or immunohistochemical algorithms of Visco-Young and/or Choi, have been described previously. ${ }^{22,23}$ This study was conducted according to the Declaration of Helsinki. All patients whose tumor samples were taken at diagnosis have provided informed consent. The study protocol and material transfer agreement were approved by the institutional review boards of all participating centers.

\section{Tissue Microarray and Immunohistochemical Assays}

Immunohistochemical analysis for p50 was performed on tissue microarrays prepared from formalin-fixed, paraffin-embedded tissue blocks from all 465 diffuse large B-cell lymphoma tumor samples using an anti-p50 antibody (Abcam, Cambridge, MA, USA) with methods previously described. ${ }^{22,23}$ The p50 nuclear expression results were estimated in increments of $10 \%$ independently by a group of hematopathologists (CYO and KHY), and any disagreements were resolved by simultaneous review using a multi-headed microscope. The cutoff of $\mathrm{p} 50^{+}$ nuclear expression (p50 activation) was set at $\geq 20 \%$ 
based on the prognostic analyses by X-tile software (Yale University, New Haven, CT, USA). ${ }^{20,21}$

\section{TP53 Mutation and Fluorescence In Situ Hybridization Analysis}

Genomic DNA extracted from formalin-fixed, paraffin-embedded tissues was used for TP53 exon sequencing analysis using the AmpliChip system (Roche Molecular Systems, Pleasanton, CA, USA). ${ }^{23}$ Probes and methods of fluorescence in situ hybridization analysis for $M Y C, B C L 2$, and BCL6 translocation were described previously. ${ }^{24}$

\section{Gene Expression Profiling}

Total RNAs were extracted from formalin-fixed, paraffin-embedded tissues. Affymetrix GeneChip Human Genome U133 Plus 2.0 array (Santa Clara, CA, USA) were used for gene expression profiling as described previously (GSE \#31312). ${ }^{22,23}$ The gene expression profiles were available for 453 patients of the study cohort. The microarray data were quantified and normalized by the frozen robust multiarray analysis algorithm. The differentially expressed genes were identified by using multiple $t$-tests. The $P$-values obtained via multiple $t$-tests were corrected for false discovery rates using the beta-uniform mixture method.

\section{Statistical Analysis}

The clinical and pathologic features at diagnosis were compared between the subgroups using the chisquare test. Associations between p50 and expression of other proteins were evaluated with unpaired $t$-tests. Overall survival was calculated from the date of diagnosis to the date of last follow-up or death. Progression-free survival was defined from the date of diagnosis to the date of disease progression or death. Kaplan-Meier curves for overall survival and progression-free survival were created using GraphPad Prism 6 (GraphPad Software, San Diego, CA, USA), and differences were compared using the logrank (Cox-Mantel) test. Multivariate Cox proportional hazard regression analyses were conducted with SPSS software (version 19.0; IBM Corporation, Armonk, NY, USA). $P$-values of $\leq 0.05$ were considered statistically significant.

\section{Results}

p50 Nuclear Expression is More Common in Patients with the Activated B-Cell-Like Subtype of Diffuse Large B-Cell Lymphoma

We used immunohistochemistry (Figure 1a) to analyze for nuclear expression of p50, which we used as a surrogate for p50 activation. ${ }^{25}$ A total of 465 diffuse large B-cell lymphoma samples were
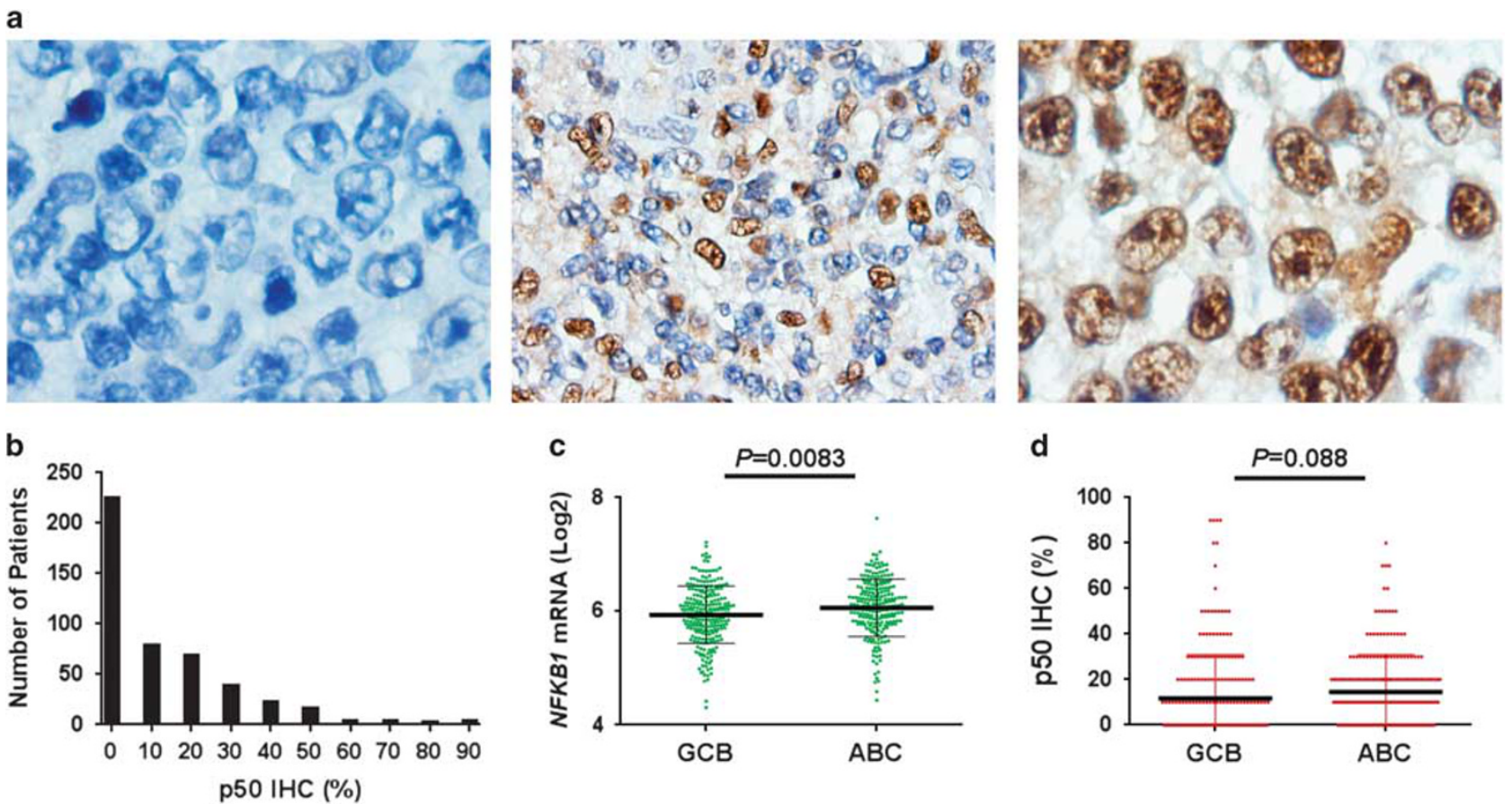

Figure 1 p50 nuclear expression and NFKB1 mRNA expression in diffuse large B-cell lymphoma (DLBCL). (a) Representative immunohistochemical stains (IHC) for p50 nuclear expression of $0 \%(100 \times), 20 \%(60 \times)$, and $100 \%(100 \times)$, respectively. (b) Histogram of p50 nuclear expression in the studied diffuse large B-cell lymphoma cohort. (c) The mean level of NFKB1 mRNA expression was significantly higher in activated B-cell-like (ABC) diffuse large B-cell lymphoma than in germinal center B-cell-like (GCB) diffuse large B-cell lymphoma. (d) The mean level of p50 nuclear expression was higher in activated B-cell-like diffuse large B-cell lymphoma than in germinal center B-cell-like diffuse large B-cell lymphoma but it was not statistically significant. 
Table 1 Clinical and molecular characteristics of studied p50+ and p50- patients with de novo diffuse large B-cell lymphoma (DLBCL; $N=465$ )

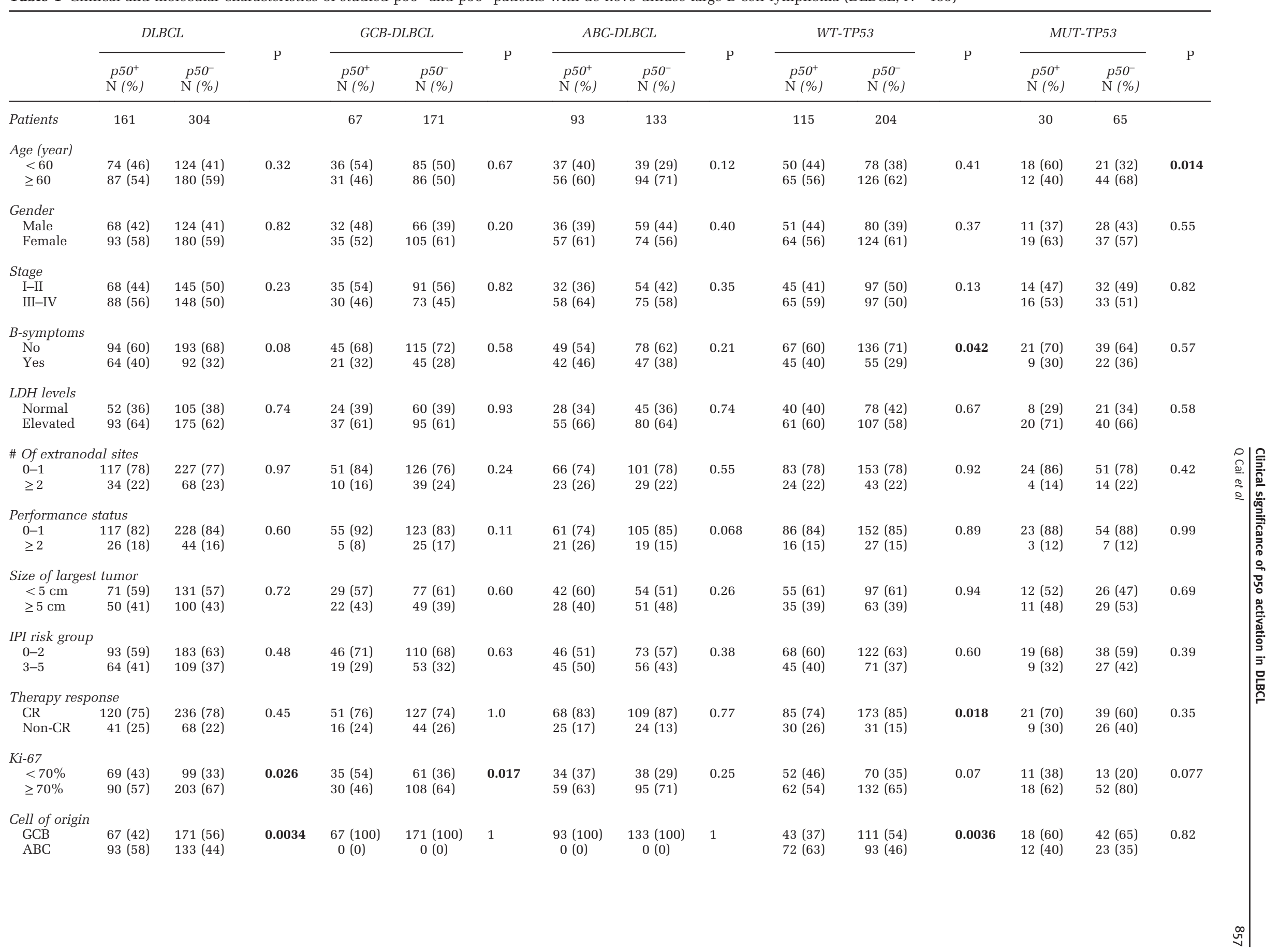


Table 1 (Continued)

\begin{tabular}{|c|c|c|c|c|c|c|c|c|c|c|c|c|c|c|c|}
\hline & \multicolumn{2}{|c|}{$D L B C L$} & \multirow{2}{*}{$\mathrm{P}$} & \multicolumn{2}{|c|}{$G C B-D L B C L$} & \multirow{2}{*}{$\mathrm{P}$} & \multicolumn{2}{|c|}{$A B C-D L B C L$} & \multirow{2}{*}{$\mathrm{P}$} & \multicolumn{2}{|c|}{ WT-TP53 } & \multirow{2}{*}{$\mathrm{P}$} & \multicolumn{2}{|c|}{ MUT-TP53 } & \multirow{2}{*}{$\mathrm{P}$} \\
\hline & $\begin{array}{c}p 50^{+} \\
\mathrm{N}(\%)\end{array}$ & $\begin{array}{c}p 50^{-} \\
\mathrm{N}(\%)\end{array}$ & & $\begin{array}{c}p 50^{+} \\
\mathrm{N}(\%)\end{array}$ & $\begin{array}{c}p 50^{-} \\
\mathrm{N}(\%)\end{array}$ & & $\begin{array}{c}p 50^{+} \\
\mathrm{N}(\%)\end{array}$ & $\begin{array}{c}p 50^{-} \\
\mathrm{N}(\%)\end{array}$ & & $\begin{array}{c}p 50^{+} \\
\mathrm{N}(\%)\end{array}$ & $\begin{array}{c}p 50^{-} \\
\mathrm{N}(\%)\end{array}$ & & $\begin{array}{c}p 50^{+} \\
\mathrm{N}(\%)\end{array}$ & $\begin{array}{c}p 50^{-} \\
\mathrm{N}(\%)\end{array}$ & \\
\hline \multicolumn{16}{|c|}{ TP53 mutations } \\
\hline- & 115 (79) & $204(76)$ & 0.46 & $43(71)$ & 111 (73) & 0.76 & $72(86)$ & $93(80)$ & 0.31 & 115 (100) & $204(100)$ & 1 & $0(0)$ & $0(0)$ & 1 \\
\hline \multirow{2}{*}{\multicolumn{16}{|c|}{ p53 expression }} \\
\hline & & & & & & & & & & & & & & & \\
\hline $\begin{array}{l}<20 \% \\
\geq 20 \%\end{array}$ & $\begin{array}{r}101(71) \\
41(29)\end{array}$ & $\begin{array}{l}160(61) \\
103(39)\end{array}$ & 0.04 & $\begin{array}{l}41(70) \\
18(30)\end{array}$ & $\begin{array}{l}87(58) \\
62(42)\end{array}$ & 0.16 & $\begin{array}{l}60(72) \\
23(28)\end{array}$ & $\begin{array}{l}73(64) \\
41(36)\end{array}$ & 0.28 & $\begin{array}{l}90(80) \\
23(20)\end{array}$ & $\begin{array}{r}143(71) \\
57(29)\end{array}$ & 0.14 & $\begin{array}{l}11(38) \\
18(62)\end{array}$ & $\begin{array}{l}17(27) \\
46(73)\end{array}$ & 0.33 \\
\hline \multicolumn{16}{|c|}{ MYC translocation } \\
\hline- & 101 (91) & $174(86)$ & 0.28 & $36(86)$ & $89(82)$ & 0.81 & $65(94)$ & $85(90)$ & 0.56 & 77 (91) & $125(88)$ & 0.66 & $17(90)$ & $32(84)$ & 0.71 \\
\hline+ & $10(9)$ & $28(14)$ & & $6(14)$ & $19(18)$ & & $4(6)$ & $9(10)$ & & $8(9)$ & $17(12)$ & & $2(10)$ & $6(16)$ & \\
\hline \multicolumn{16}{|c|}{ BCL2 translocation } \\
\hline- & $123(89)$ & $181(77)$ & 0.004 & $42(76)$ & $89(64)$ & 0.12 & $81(98)$ & $103(94)$ & 0.30 & $91(89)$ & $138(78)$ & 0.023 & $24(89)$ & $38(73)$ & 0.15 \\
\hline+ & $15(11)$ & $56(23)$ & & $13(24)$ & $49(36)$ & & $2(2)$ & $7(6)$ & & $11(11)$ & $38(22)$ & & $3(11)$ & $14(27)$ & \\
\hline \multicolumn{16}{|c|}{ BCL6 translocation } \\
\hline- & $74(64)$ & $146(68)$ & 0.48 & $35(86)$ & $92(76)$ & 0.67 & $38(58)$ & $54(58)$ & 0.95 & $54(66)$ & $96(66)$ & 0.99 & $14(61)$ & $36(77)$ & 0.17 \\
\hline+ & $41(36)$ & $68(32)$ & & $13(14)$ & $29(24)$ & & $28(42)$ & $39(42)$ & & $28(34)$ & $50(34)$ & & $9(39)$ & $11(23)$ & \\
\hline \multicolumn{16}{|c|}{ Myc expression } \\
\hline$<70 \%$ & $118(75)$ & $192(64)$ & 0.016 & $52(81)$ & 117 (69) & 0.07 & $66(71)$ & $75(56)$ & 0.036 & 83 (73) & $135(67)$ & 0.25 & $25(86)$ & $34(52)$ & 0.0023 \\
\hline$\geq 70 \%$ & $40(25)$ & $110(36)$ & & $12(19)$ & $52(31)$ & & 27 (29) & $58(44)$ & & $30(27)$ & $67(33)$ & & $4(14)$ & $31(48)$ & \\
\hline \multicolumn{16}{|c|}{ Bcl-2 expression } \\
\hline$<70 \%$ & $88(56)$ & $154(51)$ & 0.38 & $47(72)$ & $97(58)$ & 0.05 & $40(43)$ & $57(43)$ & 1.0 & $63(55)$ & $109(54)$ & 0.91 & $19(63)$ & $26(40)$ & 0.047 \\
\hline$\geq 70 \%$ & $70(44)$ & $146(49)$ & & $18(28)$ & $71(42)$ & & $52(57)$ & $75(57)$ & & $51(45)$ & $93(46)$ & & $11(37)$ & $39(60)$ & \\
\hline \multicolumn{16}{|c|}{ Bcl-6 expression } \\
\hline$\leq 50 \%$ & $70(44)$ & $98(32)$ & 0.014 & $23(35)$ & $36(21)$ & 0.029 & $47(50)$ & $62(47)$ & 0.68 & $50(44)$ & $61(30)$ & 0.015 & $14(48)$ & $21(32)$ & 0.17 \\
\hline$>50 \%$ & $88(56)$ & 204 (68) & & $42(65)$ & $134(79)$ & & $46(50)$ & $70(53)$ & & $64(56)$ & $142(70)$ & & $15(52)$ & $44(68)$ & \\
\hline \multicolumn{16}{|c|}{ GCET1 expression } \\
\hline$<50 \%$ & $121(78)$ & $183(61)$ & 0.0003 & $40(61)$ & $72(43)$ & 0.013 & $81(90)$ & $111(85)$ & 0.31 & $88(79)$ & $125(62)$ & 0.0036 & $23(79)$ & $36(55)$ & 0.037 \\
\hline$\geq 50 \%$ & $34(22)$ & 117 (39) & & $25(39)$ & $97(57)$ & & $9(10)$ & $20(15)$ & & $24(21)$ & 75 (38) & & $6(21)$ & $29(45)$ & \\
\hline \multicolumn{16}{|c|}{ CD10 expression } \\
\hline$<50 \%$ & $114(72)$ & $168(55)$ & 0.0006 & $32(48)$ & $43(25)$ & 0.001 & $82(88)$ & $125(94)$ & 0.15 & $82(72)$ & $119(59)$ & 0.021 & $19(63)$ & $32(49)$ & 0.27 \\
\hline$\geq 50 \%$ & $45(28)$ & $135(45)$ & & $34(52)$ & $127(75)$ & & $11(12)$ & $8(6)$ & & $32(28)$ & $84(41)$ & & $11(37)$ & $33(51)$ & \\
\hline \multicolumn{16}{|c|}{ FOXP1 expression } \\
\hline$<80 \%$ & $76(48)$ & $123(41)$ & 0.17 & $48(73)$ & $101(60)$ & 0.096 & $28(30)$ & $22(16)$ & 0.022 & $55(48)$ & $87(43)$ & 0.41 & $14(47)$ & $24(37)$ & 0.50 \\
\hline$\geq 80 \%$ & $83(52)$ & 177 (59) & & $18(27)$ & $66(40)$ & & $65(70)$ & $111(84)$ & & $59(52)$ & $115(57)$ & & $16(53)$ & $40(63)$ & \\
\hline MUM1 exl & sion & & & & & & & & & & & & & & \\
\hline$<60 \%$ & $92(59)$ & $178(59)$ & 1 & $51(80)$ & $142(83)$ & 0.57 & $41(45)$ & $36(27)$ & 0.0099 & $66(58)$ & $122(60)$ & 0.81 & $16(57)$ & $38(58)$ & 1 \\
\hline$\geq 60 \%$ & $64(41)$ & $126(41)$ & & $13(20)$ & 29 (17) & & $51(55)$ & $97(73)$ & & $47(42)$ & $82(40)$ & & $12(43)$ & $27(42)$ & \\
\hline BLIMP-1 e & ession & & & & & & & & & & & & & & \\
\hline$<10 \%$ & $105(68)$ & $232(78)$ & 0.023 & $50(79)$ & $146(87)$ & 0.16 & $55(60)$ & $86(67)$ & 0.39 & $70(64)$ & $152(76)$ & 0.025 & $23(77)$ & $54(86)$ & 0.38 \\
\hline$\geq 10 \%$ & $50(32)$ & $65(22)$ & & $13(21)$ & $22(13)$ & & $36(40)$ & $43(33)$ & & 39 (36) & $47(24)$ & & $7(23)$ & 9 (14) & \\
\hline
\end{tabular}


Table 1 (Continued)

\begin{tabular}{|c|c|c|c|c|c|c|c|c|c|c|c|c|c|c|c|}
\hline & \multicolumn{2}{|c|}{$D L B C L$} & \multirow{2}{*}{$P$} & \multicolumn{2}{|c|}{$G C B-D L B C L$} & \multirow{2}{*}{$\mathrm{P}$} & \multicolumn{2}{|c|}{$A B C-D L B C L$} & \multirow{2}{*}{$\mathrm{P}$} & \multicolumn{2}{|c|}{ WT-TP53 } & \multirow{2}{*}{$\mathrm{P}$} & \multicolumn{2}{|c|}{ MUT-TP53 } & \multirow{2}{*}{$\mathrm{P}$} \\
\hline & $\begin{array}{c}p 50^{+} \\
\mathrm{N}(\%)\end{array}$ & $\begin{array}{c}p 50^{-} \\
\mathrm{N}(\%)\end{array}$ & & $\begin{array}{c}p 50^{+} \\
\mathrm{N}(\%)\end{array}$ & $\begin{array}{c}p 50^{-} \\
\mathrm{N}(\%)\end{array}$ & & $\begin{array}{c}p 50^{+} \\
\mathrm{N}(\%)\end{array}$ & $\begin{array}{c}p 50^{-} \\
\mathrm{N}(\%)\end{array}$ & & $\begin{array}{c}p 50^{+} \\
\mathrm{N}(\%)\end{array}$ & $\begin{array}{c}p 50^{-} \\
\mathrm{N}(\%)\end{array}$ & & $\begin{array}{c}p 50^{+} \\
\mathrm{N}(\%)\end{array}$ & $\begin{array}{c}p 50^{-} \\
\mathrm{N}(\%)\end{array}$ & \\
\hline \multicolumn{16}{|c|}{ PI3K expression } \\
\hline$<70 \%$ & $121(79)$ & $191(68)$ & 0.02 & $51(79)$ & $117(74)$ & 0.50 & $70(79)$ & $77(61)$ & 0.0074 & $89(80)$ & $131(67)$ & 0.025 & $21(75)$ & $42(69)$ & 0.62 \\
\hline$\geq 70 \%$ & $33(21)$ & $92(32)$ & & $14(21)$ & $42(26)$ & & $19(21)$ & $50(39)$ & & $23(20)$ & $64(33)$ & & $7(25)$ & $19(31)$ & \\
\hline \multicolumn{16}{|c|}{$p-A K T$ expression } \\
\hline$\leq 30 \%$ & $112(71)$ & $174(59)$ & 0.014 & $49(77)$ & $97(58)$ & 0.014 & $62(67)$ & $77(60)$ & 0.33 & $79(69)$ & $114(58)$ & 0.052 & $23(82)$ & $41(66)$ & 0.14 \\
\hline$>30 \%$ & $46(29)$ & $121(41)$ & & $15(23)$ & $69(42)$ & & $31(33)$ & $52(40)$ & & $35(31)$ & $84(42)$ & & 5 (18) & $21(34)$ & \\
\hline \multicolumn{16}{|c|}{ CXCR4 expression } \\
\hline$<20 \%$ & $119(78)$ & $185(66)$ & 0.008 & $53(83)$ & $117(74)$ & 0.22 & $66(75)$ & $68(55)$ & 0.0037 & $91(81)$ & $126(65)$ & 0.0038 & $16(59)$ & $40(66)$ & 0.63 \\
\hline$\geq 20 \%$ & $33(22)$ & $96(34)$ & & $11(17)$ & $40(26)$ & & $22(25)$ & $56(45)$ & & 21 (19) & $67(35)$ & & $11(41)$ & $21(34)$ & \\
\hline \multicolumn{16}{|c|}{ Nuclear p52 expression } \\
\hline$<10 \%$ & $92(60)$ & $217(76)$ & 0.0006 & $35(57)$ & $120(76)$ & 0.0083 & $57(63)$ & $97(77)$ & 0.024 & $64(59)$ & $150(77)$ & 0.001 & $18(62)$ & $45(75)$ & 0.22 \\
\hline$\geq 10 \%$ & $61(40)$ & $67(24)$ & & $26(43)$ & $38(24)$ & & $34(37)$ & $29(23)$ & & $45(41)$ & $44(23)$ & & $11(38)$ & $15(25)$ & \\
\hline \multicolumn{16}{|c|}{ Nuclear p65 expression } \\
\hline$<10 \%$ & $42(26)$ & $114(49)$ & $<0.0001$ & $13(20)$ & $74(46)$ & 0.0003 & $29(31)$ & $70(53)$ & 0.0016 & $32(28)$ & $109(55)$ & $<0.0001$ & $7(24)$ & $23(37)$ & 0.34 \\
\hline$\geq 10 \%$ & $118(74)$ & $149(51)$ & & $53(80)$ & $87(54)$ & & $64(69)$ & $62(47)$ & & $83(72)$ & $88(45)$ & & $22(76)$ & $40(63)$ & \\
\hline \multicolumn{16}{|c|}{ Nuclear c-Rel expression } \\
\hline$<10 \%$ & $90(58)$ & $225(76)$ & 0.0001 & $40(62)$ & $124(75)$ & 0.075 & $50(56)$ & $101(78)$ & 0.0007 & $65(60)$ & $152(77)$ & 0.0025 & $17(57)$ & $45(70)$ & 0.24 \\
\hline$\geq 10 \%$ & $65(42)$ & $71(24)$ & & $24(38)$ & $42(25)$ & & $40(44)$ & $29(22)$ & & $44(40)$ & $46(23)$ & & $13(43)$ & $19(30)$ & \\
\hline
\end{tabular}

Abbreviations: ABC, activated B-cell-like; CR, complete remission; GCB, germinal center B-cell-like; IPI, International Prognostic Index; LDH, lactate dehydrogenase; MUT-TP53; mutated TP53; p-AKT, phospho-AKT; PR, partial response; WT-TP53, wild-type TP53.

Bold values are statistically significant. 
evaluated and the clinical features of these cases were shown in Table 1 . We considered a sample in which $\geq 20 \%$ of tumor cells had positive nuclear staining for p50 to have high p50 nuclear expression and p50 activation $\left(\mathrm{p} 50^{+}\right)$. Using this cutoff, 161

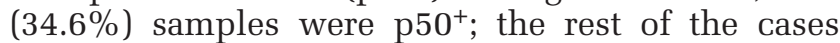
$(65.4 \%)$ having no or low p50 nuclear expression with or without cytoplasmic staining were $\mathrm{p} 50^{-}$ (Figure 1b). The ${\mathrm{p} 50^{+}}^{+}$tumors were more often of activated B-cell-like than germinal center B-cell-like subtype ( $58 \%$ vs $42 \%$, Table 1), which accounted for $41 \%$ of the activated B-cell-like diffuse large B-cell lymphoma cases and $28 \%$ of the germinal center B-cell-like diffuse large B-cell lymphoma cases. At the transcriptional level, NFKB1 mRNA expression was significantly higher in the activated B-cell-like diffuse large B-cell lymphoma subtype than in the germinal center B-cell-like subtype $(P=0.0083$; Figure 1c). Correspondingly, the activated B-cell-like diffuse large B-cell lymphoma group had a higher mean level of p50 nuclear expression (15\%) than the germinal center B-cell-like diffuse large B-cell lymphoma group $(12 \% ; P=0.088$; Figure $1 \mathrm{~d})$.

\section{Nuclear p50 Expression Correlates with Shorter Survival Durations in Patients with Wild-Type TP53 but Longer Survival Durations and Decreased p53, Myc, and Bcl-2 Expression in Patients with Mutated TP53}

Nuclear expression of p50 did not correlate with overall survival or progression-free survival rates in the overall study cohort (overall survival, $P=0.54$; progression-free survival, $P=0.74$ ), nor in the germinal center B-cell-like diffuse large B-cell lymphoma (overall survival, $P=0.48$; progression-free survival, $P=0.32$ ) and activated B-cell-like diffuse large B-cell lymphoma subsets (overall survival, $P=0.25$; progression-free survival, $P=0.29$ ) as previously described. ${ }^{21}$ However, controlling the prognostic factor of TP53 mutation, we found in the subset with wild-type TP53 (WT-TP53), p50 ${ }^{+}$status conferred significantly lower overall survival and progression-free survival rates of diffuse large B-cell lymphoma patients (overall survival, $P=0.0024$, Figure 2a; progression-free survival, $P=0.018$ ), independent of cell of origin (figures not shown). In contrast, in patients with mutated TP53 (MUTTP53), $\mathrm{p50}^{+}$status correlated with significantly higher survival rates (overall survival, $P=0.0089$, Figure 2b; progression-free survival, $P=0.05$ ), which was restricted to the germinal center B-cell-like subtype. The $\mathrm{p}^{+} 0^{+}$patients with MUT-TP53 germinal center B-cell-like diffuse large B-cell lymphoma had significantly better survival than $\mathrm{p}^{-} 0^{-}$patients with MUT-TP53 germinal center B-cell-like diffuse large B-cell lymphoma (overall survival, $P=0.001$, Figure 2c; progression-free survival, $P=0.014$ ), and better overall survival (but not progression-free survival) than $\mathrm{p}^{+} 0^{+}$patients with WT-TP53 germinal center B-cell-like diffuse large B-cell lymphoma $(P=0.05$, Figure $2 \mathrm{~d})$. The favorable prognosis associated with $\mathrm{p}^{+} 0^{+}$status remained significant in patients with high levels $(\geq 20 \%)$ of MUT-p53 expression (overall survival, $P=0.0074$, Figure 2e; progression-free survival, $P=0.019$ ). TP53 mutation status was a significant adverse prognostic factor in p50 ${ }^{-}$patients (overall survival, $P<0.0001$, Figure 2b; progression-free survival, $P<0.0001$, Figure 2f) but not in $\mathrm{p}^{+} 0^{+}$patients $(P=0.14$ for a trend of better overall survival, Figure $2 b ; \mathrm{P}=0.53$ for progression-free survival, figures not shown).

The clinicopathologic features of $\mathrm{p}^{+} 0^{+}$and $\mathrm{p}^{-} 0^{-}$ patients with WT-TP53 or MUT-TP53 were shown in Table 1. Among diffuse large B-cell lymphoma patients with MUT-TP53, p50+ status was associated with younger age ( $<60$ years, $P=0.042)$ and lower frequency of Myc $(P=0.0023)$ and Bcl-2 $(P=0.047)$ overexpression (Table 1), which may contribute to the favorable prognostic effects. However, the difference in proportion of young patients between the

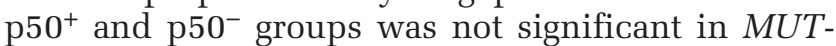
TP53 germinal center B-cell-like diffuse large B-cell lymphoma ( $61 \%$ vs $43 \%, P=0.26)$; and after excluding patients with low Myc or Bcl-2 expression, $\mathrm{p} 50^{+}$ status still correlated with significantly better survival rates in patients with MUT-TP53 germinal center B-cell-like diffuse large B-cell lymphoma (Figure $2 \mathrm{~g}$ and h).

Notably, in the overall diffuse large B-cell lym-

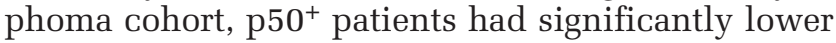
levels of p53 protein expression than did p50patients (Figure 3a). This difference was more pronounced in the subset of patients with MUTTP53 ( $P=0.045$, Figure $3 \mathrm{~b})$ especially those with overexpressed MUT-p53 $(P=0.021$, Figure 3c), and also was more apparent in the germinal center

Figure 2 Prognostic effects of p50 nuclear expression in diffuse large B-cell lymphoma (DLBCL). (a) In diffuse large B-cell lymphoma patients with wild-type TP53 (WT-TP53), p50 $0^{+}$status correlated with significantly poorer overall survival (OS). (b) In contrast, p50 ${ }^{+}$status correlated with significantly better overall survival in diffuse large B-cell lymphoma patients with mutated TP53 (MUT-TP53). TP53 mutation had significant adverse impact only in patients with ${\mathrm{p} 50^{-} \text {diffuse large B-cell lymphoma but not in p50 }}^{+}$germinal center B-celllike diffuse large B-cell lymphoma. (c) In germinal center B-cell-like (GCB) diffuse large B-cell lymphoma patients with MUT-TP53, p50 status correlated with significantly better overall survival. (d) MUT-TP53 patients with p50+ germinal center B-cell-like diffuse large B-cell lymphoma had significantly better overall survival than WT-TP53 patients with p50 ${ }^{+}$germinal center B-cell-like diffuse large B-cell lymphoma. (e) In germinal center B-cell-like diffuse large B-cell lymphoma patients with overexpression $(\geq 20 \%)$ of mutated-p53, p50 status correlated with significantly better overall survival. (f) In diffuse large B-cell lymphoma patients without p50 ${ }^{+}$nuclear expression, TP53 mutation status correlated with significantly worse progression-free survival (PFS). (g and h) Excluding patients with low Bcl-2 or Myc expression in the MUT-TP53 germinal center B-cell-like diffuse large B-cell lymphoma subgroup, p50 ${ }^{+}$status still correlated with significantly better overall survival. 
B-cell-like subtype (Figure 3d). Moreover, at the transcription level, in patients with WT-TP53 germinal center B-cell-like diffuse large B-cell lymphoma, $\mathrm{p}^{+} 0^{+}$nuclear expression was associated with TP53 downregulation (Figure 3e). However,

a

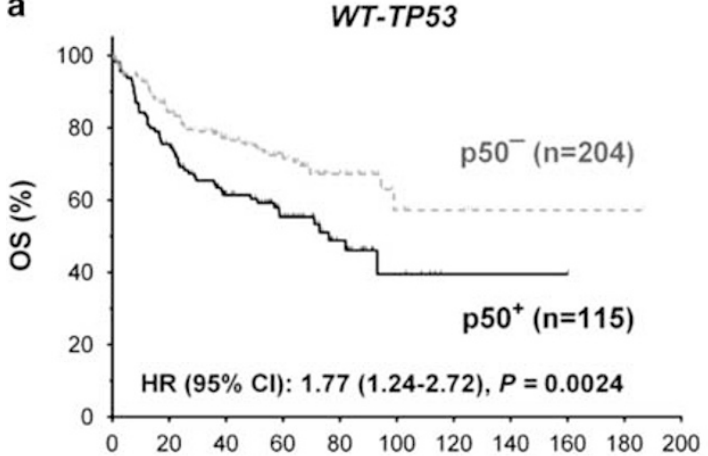

C

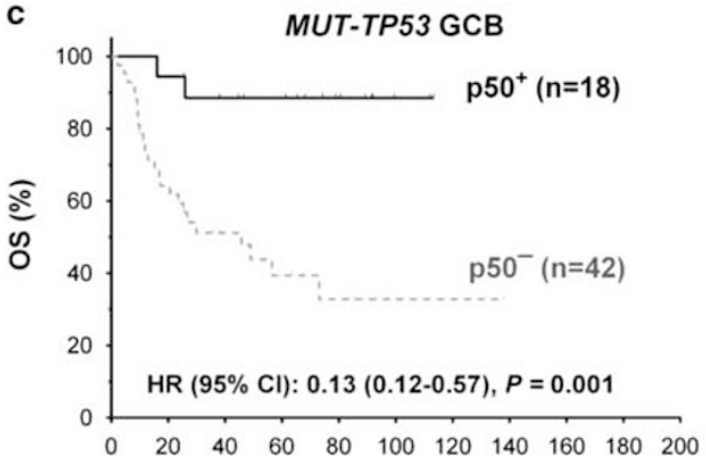

e
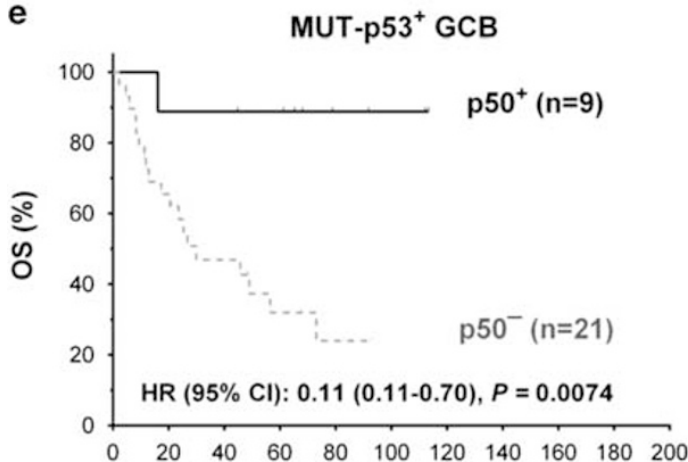

g

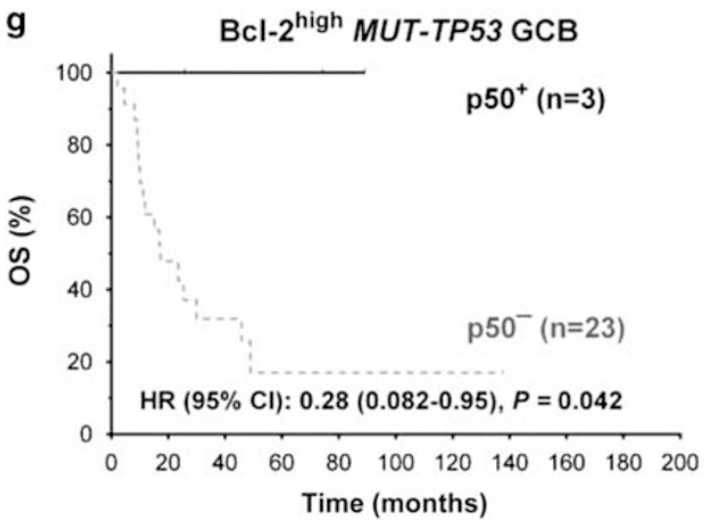

trends of TP53 upregulation was associated with $\mathrm{p}^{+} 0^{+}$nuclear expression in patients with WT-TP53 activated B-cell-like diffuse large B-cell lymphoma $(P=0.069$, Figure 3f) and in patients with $M U T-T P 53$ $(P=0.13)$, and such a correlation was significant in
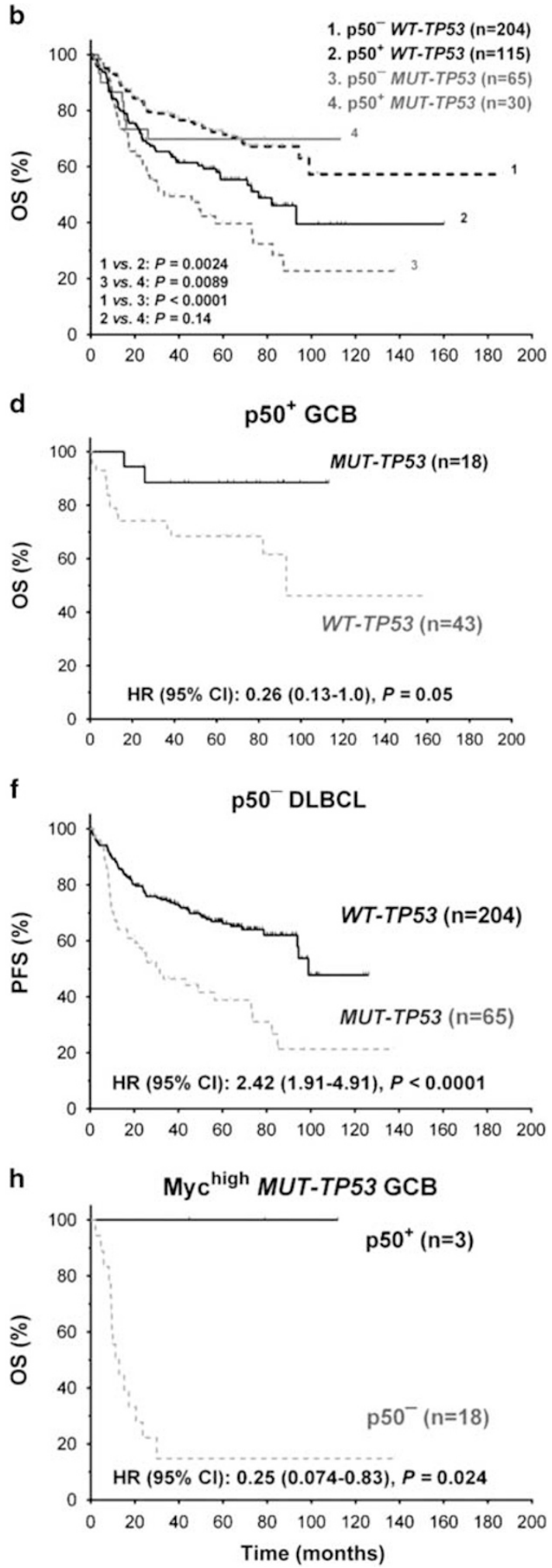

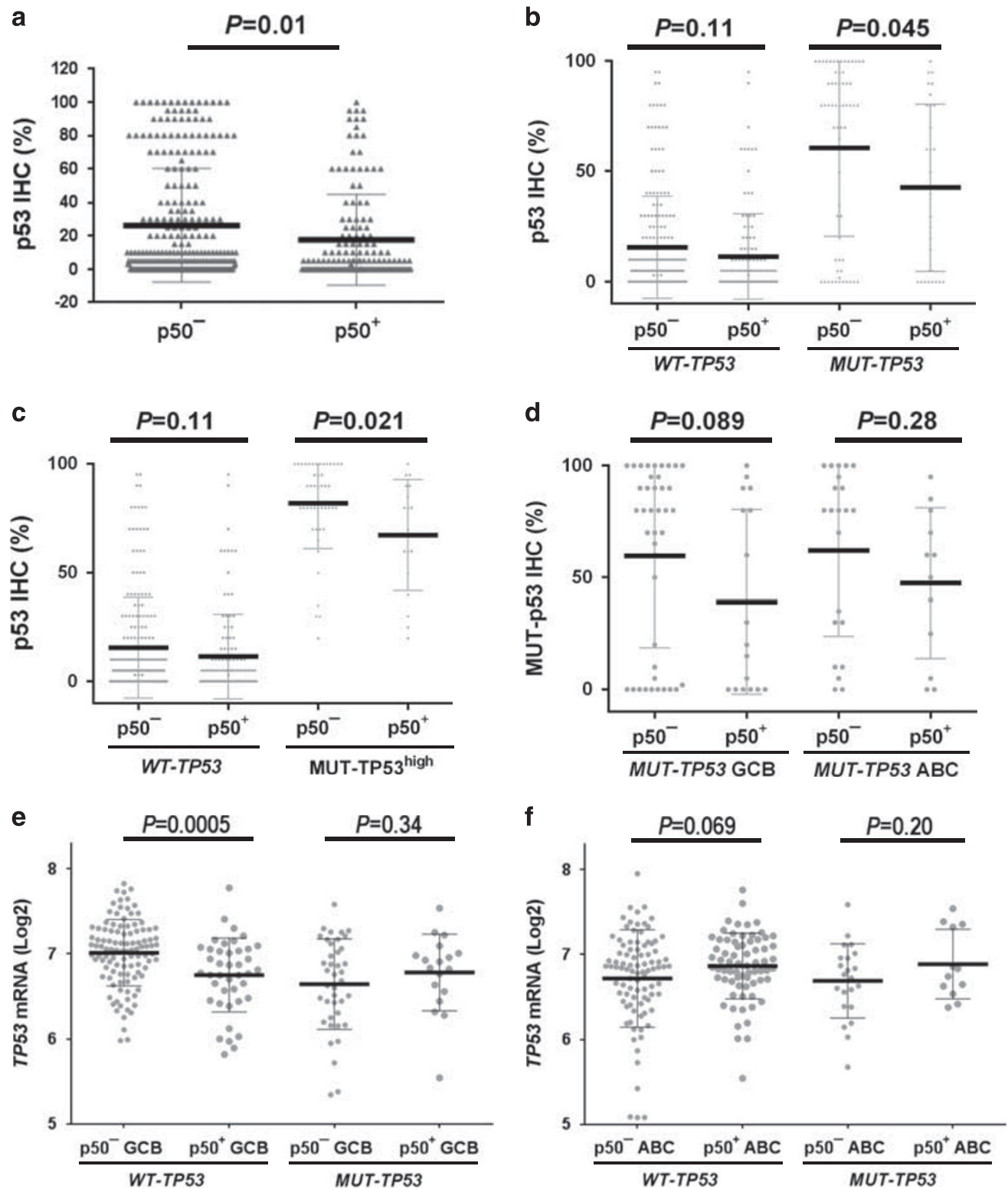

Figure 3 Correlations between p50 nuclear expression and expression of TP53 in diffuse large B-cell lymphoma (DLBCL). (a) p50 ${ }^{+}$status in overall diffuse large B-cell lymphoma was associated with significantly lower levels of p53 expression. (b-d) In diffuse large B-cell lymphoma patients with mutated (MUT) p53, p50 $0^{+}$status was associated with significantly lower levels of MUT-p53 expression. This reduced MUT-p53 expression remained significant for the cases with overexpressed MUT-p53 ( $\geq 20 \%$, MUT-p53high), and was more apparent in the germinal center B-cell-like (GCB) subtype. (e and f) p50 $0^{+}$status was associated with TP53 downregulation only in the germinal center B-cell-like diffuse large B-cell lymphoma subgroup with wild-type TP53 (WT-TP53), but not in the MUT-TP53 diffuse large B-cell lymphoma patients.

the overall activated B-cell-like diffuse large B-cell lymphoma $(P=0.029)$.

Nuclear p50 Expression Correlates with Decreased Myc, PI3K, p-AKT, and CXCR4 Expression in Patients with Wild-Type TP53 and Multivariate Survival Analysis

We examined whether p50 nuclear expression was associated with any potentially confounding prognostic factors that have been described. The molecular characteristics of the studied patients are shown in Table 1 . We found $\mathrm{p} 50^{+}$status was only associated with expression of the NF- $\kappa \mathrm{B}$ subunits p65, p52, and c-Rel and tumor-suppressor BLIMP-1, but not associated with the presence of other adverse

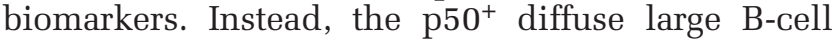
lymphoma group less frequently had BCL2 translocations and Ki-67 (an indicator of cell proliferation), p53, Myc, PI3K, phospho-AKT (p-AKT), and CXCR4 (ref. 26) overexpression (Table 1). Comparisons

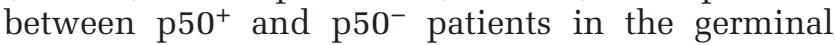
center B-cell-like and activated B-cell-like subtypes individually showed that in germinal center B-celllike diffuse large B-cell lymphoma, p50 ${ }^{+}$patients less 
frequently overexpressed Bcl-2, p-AKT, Bcl-6, GCET1, and CD10, but more frequently overexpressed nuclear p52 (43\% vs $24 \%)$ and p65
(80\% vs 54\%) than did the p50 ${ }^{-}$germinal center B-cell-like diffuse large B-cell lymphoma patients. In activated B-cell-like diffuse large B-cell lymphoma,
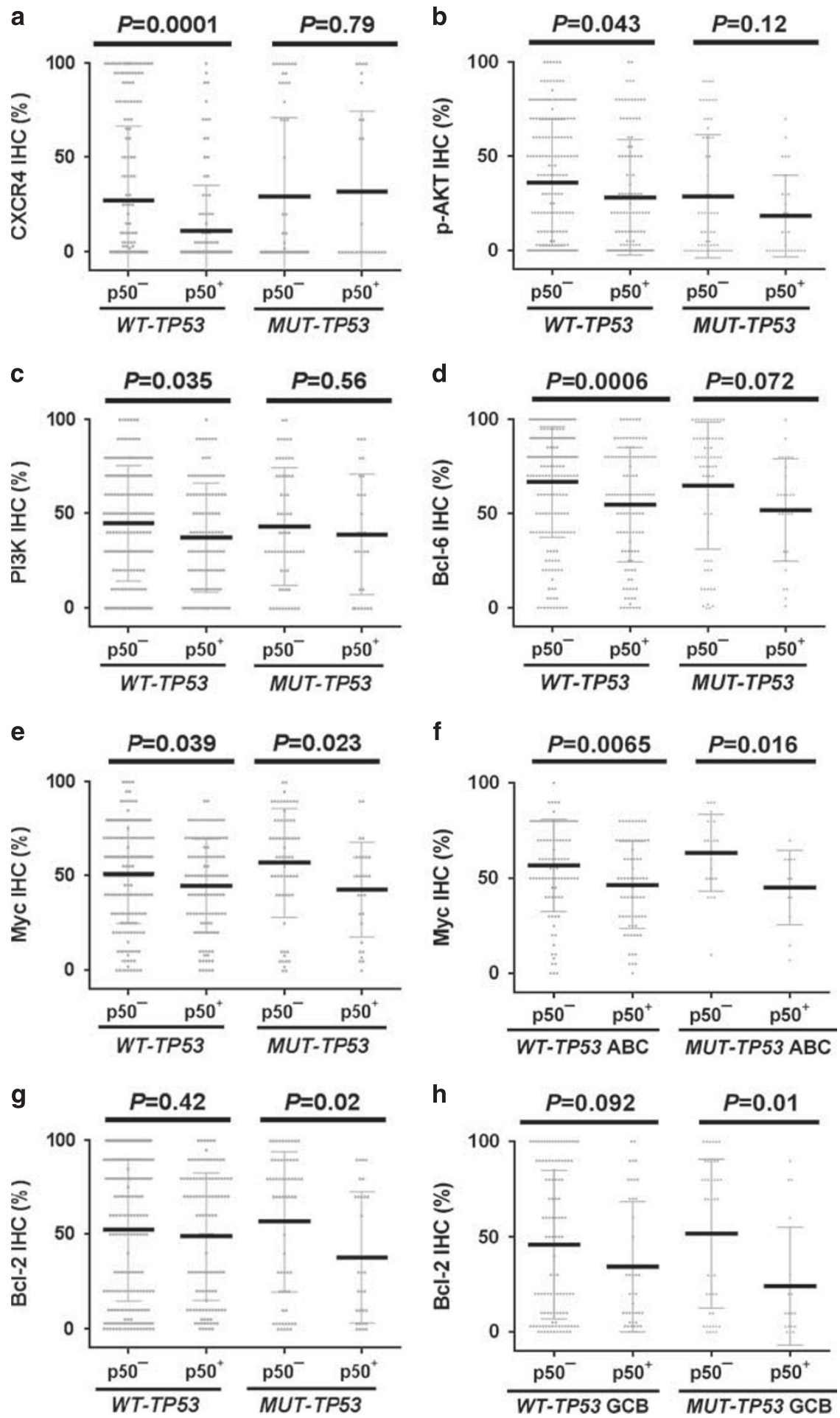

Figure 4 Negative correlations between p50 nuclear expression and expression of CXCR4, phospho-AKT (p-AKT), PI3K, Bcl-6, Myc, and Bcl-2 in diffuse large B-cell lymphoma (DLBCL) with wild-type TP53 (WT-TP53) or mutated TP53 (MUT-TP53). (a-d) In the WT-TP53 subgroup, $\mathrm{p}^{+} 0^{+}$status was associated with significantly lower levels of CXCR4, p-AKT, PI3K, and Bcl-6. (e and f) In the overall and the activated B-cell-like (ABC) subtype of diffuse large B-cell lymphoma, p50 ${ }^{+}$status was associated with significantly lower Myc levels in both the WT-TP53 and MUT-TP53 subgroups. (g) p50 ${ }^{+}$status was associated with significantly lower Bcl-2 levels in the MUT-TP53 (but not in the WT-TP53) subgroup. (h) In germinal center B-cell-like (GCB) diffuse large B-cell lymphoma, p50 ${ }^{+}$status was associated with significantly lower Bcl-2 levels in the MUT-TP53 subgroup, and a trend of decrease in the WT-TP53 subgroup. 
$\mathrm{p} 0^{+}$patients less frequently overexpressed Myc, PIK3, CXCR4, FOXP1, and MUM1, but had more frequent p65 (69\% vs 47\%), p52 (37\% vs $23 \%)$, and
c-Rel ( $44 \%$ vs $22 \%$ ) nuclear expression than observed in ${\mathrm{p} 50^{-}}^{-}$activated B-cell-like diffuse large B-cell lymphoma (Table 1). a

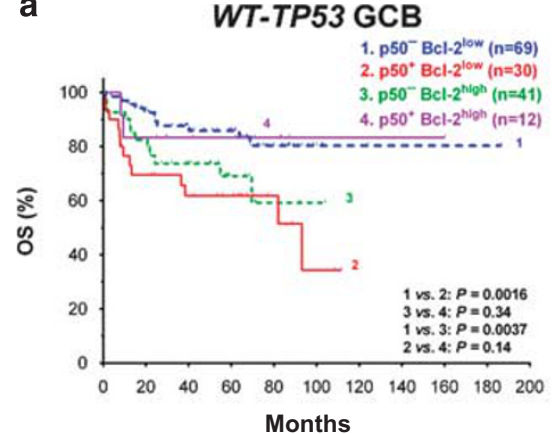

b

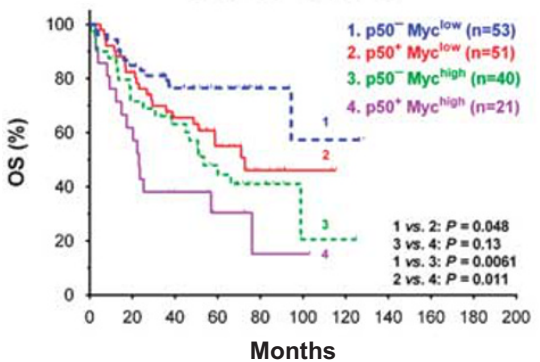

C
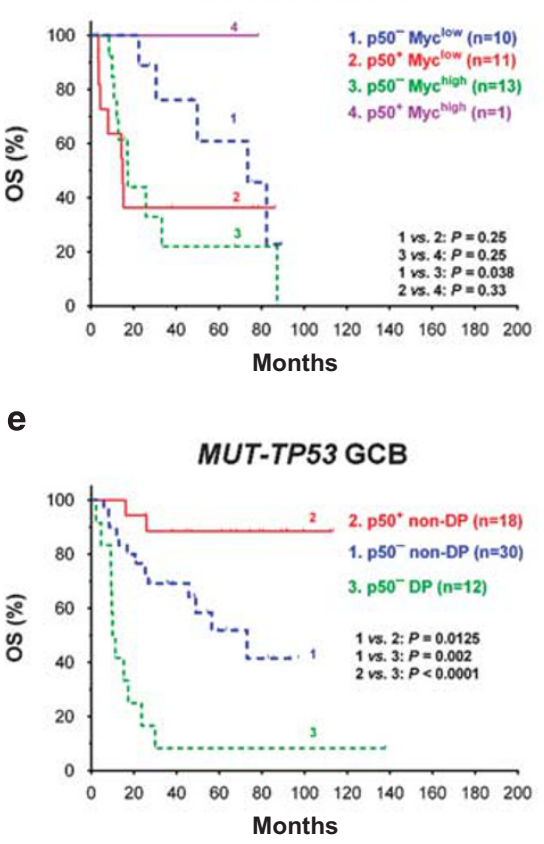

WT-TP53 GCB

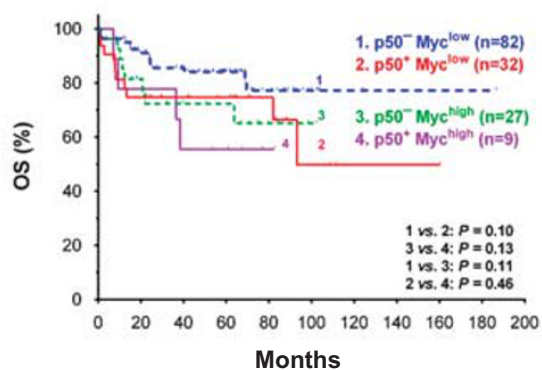

WT-TP53 ABC

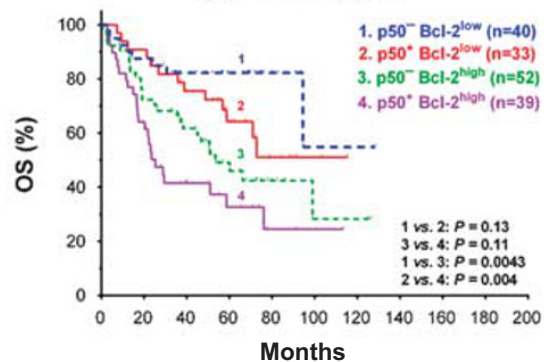

d

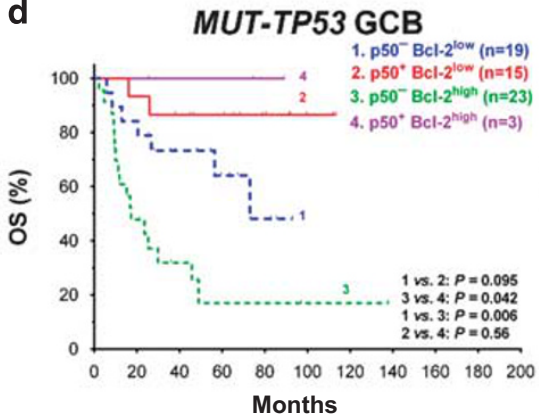

MUT-TP53 GCB

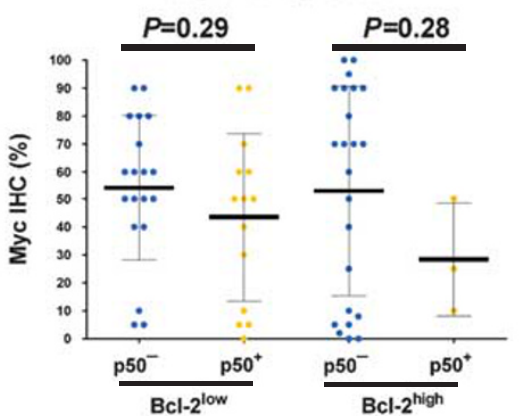

WT-TP53 GCB

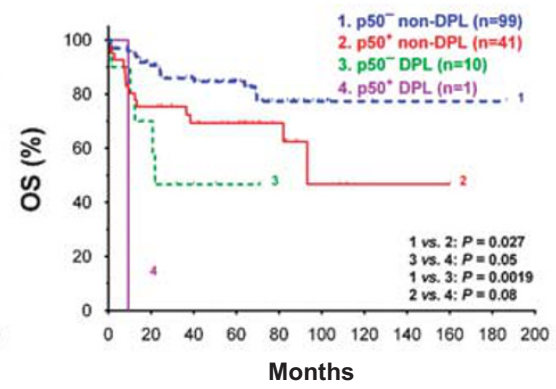

WT-TP53 ABC

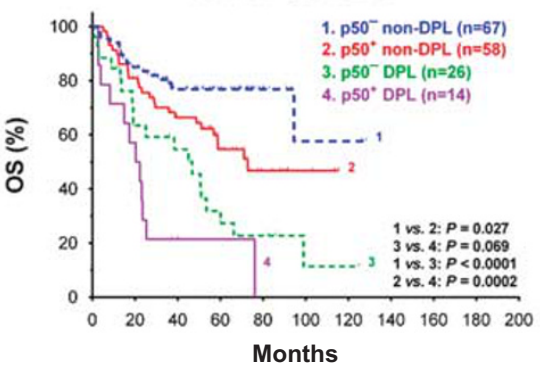

MUT-TP53 GCB

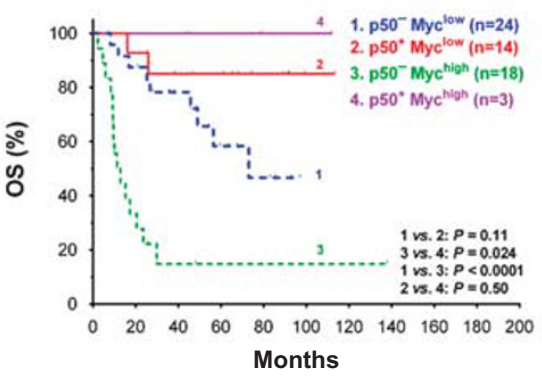

MUT-TP53 GCB

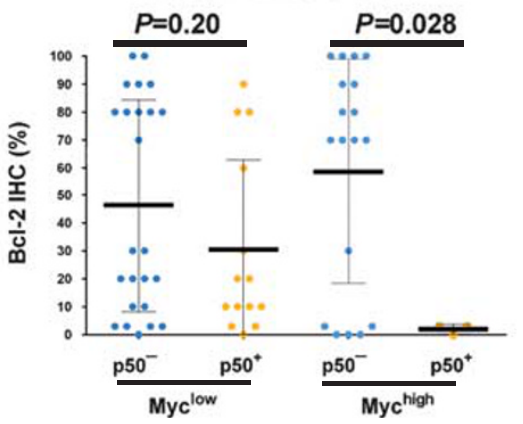

Figure 5 Prognostic analysis for p50 nuclear expression in patients with wild-type TP53 (WT-TP53) or mutated TP53 (MUT-TP53). (a) In WT-TP53 germinal center B-cell-like (GCB) diffuse large B-cell lymphoma (DLBCL), p50 positivity correlated with significant poorer survival in patients with low Bcl-2 expression (Bcl-2 $2^{\text {low}}$ ), and in patients without double-positive (Myc and Bcl-2) lymphoma (DPL, Myc ${ }^{\text {high }}$ Bcl-2 ${ }^{\text {high }}$ lymphoma). (b) In WT-TP53 activated B-cell-like diffuse large B-cell lymphoma, p50 ${ }^{+}$status correlated with significant poorer survival in patients with low Myc expression (Myc ${ }^{\text {low }}$ ), and in patients without DPL. (c) In MUT-TP53 activated B-cell-like diffuse large B-cell lymphoma, p50 positivity was associated with a trend of poorer survival in patients with low Myc expression. (d) In MUTTP53 germinal center B-cell-like diffuse large B-cell lymphoma, p50 ${ }^{+}$status correlated with significant better survival in patients with Myc $^{\text {high }}$ or Bcl-2 ${ }^{\text {high }}$ lymphoma. (e) In MUT-TP53 germinal center B-cell-like diffuse large B-cell lymphoma without concurrent high Myc and Bcl-2 expression, $\mathrm{p}^{+}$status correlated with significant better survival. Among patients with Mychigh MUT-TP53 germinal center B-cell-like diffuse large B-cell lymphoma, $\mathrm{p}^{+}$status correlated with significant lower Bcl-2 levels. 
To understand the unfavorable prognostic effects associated with p50 activation in patients with WT-TP53 diffuse large B-cell lymphoma, we restricted the molecular association analysis within the WT-TP53 subset. The p50+ WT-TP53 group had a higher proportion $(63 \%)$ of patients with the activated B-cell-like diffuse large B-cell lymphoma subtype in comparison with the p50- WT-TP53 group (46\%). The $\mathrm{p}^{+} 0^{+}$group less frequently overexpressed PI3K, p-AKT, CXCR4, GCET1, CD10, and Bcl-6 and less frequently had BCL2 translocations, whereas more frequently expressed nuclear BLIMP-1, p65 (72\% vs $45 \%$ ), p52 (41\% vs $23 \%$ ), and c-Rel ( $40 \%$ vs $23 \%$ ) than did the p50- WT-TP53 group (Table 1, Figure $4 \mathrm{a}-\mathrm{d})$. In addition, the mean level of Myc expression was significantly lower in $\mathrm{p} 50^{+}$than in $\mathrm{p} 50^{-}$diffuse large B-cell lymphoma with WT-TP53 $(P=0.039$, Figure 4e), which was significant only in the activated B-cell-like subtype $(P=0.0065$, Figure $4 f)$. The mean level of Bcl-2 expression in the p50 ${ }^{+}$WT-TP53 group also showed a trend for being lower in the germinal center B-cell-like diffuse large B-cell lymphoma subgroup $(P=0.092$, Figure $4 \mathrm{~g}$ and $\mathrm{h})$.

As Myc and Bcl-2 expression has significant impact on survival, ${ }^{27,28}$ we further analyzed the prognostic significance of p50 nuclear expression in Bcl-2 $2^{\text {low }}$ Bcl-2 ${ }^{\text {high }}$, Myc ${ }^{\text {low }}$, and $\mathrm{Myc}^{\text {high }}$ patients separately. We found that in WT-TP53 germinal center B-cell-like diffuse large B-cell lymphoma in which subset ${\mathrm{p} 50^{+}}^{+}$status was associated with a nonsignificant trend of lower Bcl-2 levels

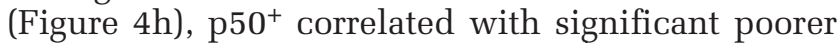
survival only in patients with Bcl-2 $2^{\text {low }}$ diffuse large B-cell lymphoma, whereas the prognostic effects were mitigated when the factor of Bcl-2 ${ }^{\text {high }}$ status was not controlled in the Myc ${ }^{\text {high }}$ and $\mathrm{Myc}^{\text {low }}$ subsets (Figure 5a). In WT-TP53 activated B-cell-like diffuse large B-cell lymphoma in which subset $\mathrm{p}^{+} 0^{+}$correlated with decreased Myc levels (Figure 4f), the prognostic significance of $\mathrm{p}^{2} 0^{+}$was less confounded when the Mychigh or concurrent $\mathrm{Myc}^{\text {high} / \mathrm{Bcl}-2^{\text {high }}}$ (ie, double-positive (DP)) status was considered (Figure 5b). Similar effects were also observed in MUT-TP53 activated B-cell-like diffuse large B-cell lymphoma (Figure 5c). In contrast, in MUT-TP53 germinal center B-cell-like diffuse large B-cell lymphoma, the favorable prognostic effects associated with $\mathrm{p}^{+} 0^{+}$were independent of both Myc and Bcl-2 levels (Figure 5d). Notably, neither of the $\mathrm{p}^{+} 0^{+} M U T$ TP53 germinal center B-cell-like diffuse large B-cell lymphoma patients had double-positive lymphoma, and among $\mathrm{Myc}^{\text {high }}$ (or Bcl-2 ${ }^{\text {high }}$ ) MUT-TP53 germinal center B-cell-like diffuse large B-cell lymphoma, ${\mathrm{p} 50^{+}}^{+}$status was still associated with significant lower Bcl-2 (or a trend of lower Myc) levels (Figure 5e).

Multivariate survival analyses for $\mathrm{p}^{+} 0^{+}$nuclear expression were performed with adjustment of clinical and molecular factors (Myc, Bcl-2, and TP53 mutation status) as shown in Table 2. p50 was an independent prognostic factor for poorer overall survival only with a borderline $P$-value in the overall diffuse large B-cell lymphoma cohort (hazard ratio, 1.45; 95\% confidence interval, 1.00-2.09; $P=0.051)$. Excluding patients with MUT-TP53, the independent prognostic impact of $\mathrm{p}^{+} 0^{+}$status becomes significant for both poorer overall survival and progression-free survival in patients with WT-TP53 $(P=0.003$ for overall survival, $P=0.012$ for progression-free survival).

When analyzed in germinal center B-cell-like and activated B-cell-like subtypes of diffuse large B-cell lymphoma individually, $\mathrm{p}^{+} 0^{+}$status was a significant independent adverse prognostic factor in activated B-cell-like diffuse large B-cell lymphoma overall $(P=0.016$ for overall survival, $P=0.042$ for progression-free survival), the WT-TP53 activated B-cell-like subset $(P=0.012$ for overall survival, $P=0.03$ for progression-free survival), and WT-TP53 germinal center B-cell-like diffuse large B-cell lymphoma (overall survival only, $P=0.044$; $P=0.21$ for progression-free survival; Table 2).

In contrast, $\mathrm{p}^{+} 0^{+}$nuclear expression showed a trend of favorable prognostic impact in patients with MUT-TP53 diffuse large B-cell lymphoma, but it was not significant $(P=0.17$ for overall survival, $P=0.18$ for progression-free survival); however, $\mathrm{p}^{+} 0^{+}$status was an independent factor for significantly better overall survival in patients with MUT-TP53 germinal center B-cell-like diffuse large B-cell lymphoma $(P=0.019$ for overall survival, $P=0.20$ for progression-free survival). In contrast, $50^{+}$nuclear expression had a trend of adverse prognostic impact in patients with MUT-TP53 activated B-cell-like diffuse large B-cell lymphoma $(P=0.11$ for overall survival, $P=0.26$ for progression-free survival; Table 2).

\section{Gene Expression Profiling Analysis Suggests Immune Regulation but not Antiapoptotic Mechanisms may Explain the Poorer Prognosis Associated with p50 Nuclear Expression}

To better understand the molecular mechanisms that underlie the prognostic significance of $\mathrm{p}^{+} 0^{+}$nuclear expression in diffuse large B-cell lymphoma patients, we compared the gene expression profiles associated with p50 $0^{+}$and $\mathrm{p} 50^{-}$tumors. With a false discovery rate cutoff of 0.01 , we found 1374,55 , and 419 transcripts were differentially expressed signifi-

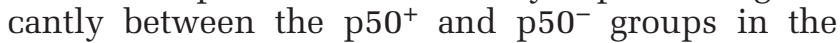
overall cohort, germinal center B-cell-like diffuse large B-cell lymphoma, and activated B-cell-like diffuse large B-cell lymphoma, respectively. Genes with high fold of differences are shown in Table 3 and Figure $6 \mathrm{a}$ and $\mathrm{b}$. These signatures were characterized by a large number of genes involved in signaling pathways and immune and inflammatory responses. Although many genes indicated immune activation, several genes associated with immunosuppressive functions were also upregulated, 
Table 2 Multivariate survival analysis for p50 nuclear expression in diffuse large B-cell lymphoma (DLBCL) treated with R-CHOP

\begin{tabular}{|c|c|c|c|c|c|c|}
\hline & \multicolumn{3}{|c|}{ OS } & \multicolumn{3}{|c|}{ PFS } \\
\hline & $H R$ & $95 \% C I$ & $\mathrm{P}$ & $H R$ & $95 \% C I$ & $\mathrm{P}$ \\
\hline \multicolumn{7}{|l|}{ In $D L B C L$} \\
\hline IPI > 2 & 2.34 & $1.63-3.37$ & $<0.001$ & 2.14 & $1.51-3.04$ & $<0.001$ \\
\hline B-symptoms & 1.57 & $1.08-2.26$ & 0.018 & 1.55 & $1.07-2.24$ & 0.02 \\
\hline Tumor size $\geq 5 \mathrm{~cm}$ & 1.17 & $0.81-1.71$ & 0.41 & 1.17 & $0.82-1.67$ & 0.39 \\
\hline Female sex & 0.76 & $0.52-1.12$ & 0.17 & 0.81 & $0.57-1.16$ & 0.25 \\
\hline TP53 mutation & 1.56 & $1.03-2.38$ & 0.038 & 1.50 & $1.02-2.20$ & 0.037 \\
\hline Mychigh & 2.38 & $1.66-3.41$ & $<0.001$ & 2.17 & $1.52-3.11$ & $<0.001$ \\
\hline Bcl-2 high & 2.34 & $1.63-3.37$ & $<0.001$ & 1.40 & $0.99-1.99$ & 0.057 \\
\hline p50 $0^{+}$ & 1.45 & $1.00-2.09$ & 0.051 & 1.30 & $0.91-1.85$ & 0.15 \\
\hline \multicolumn{7}{|l|}{ In $A B C-D L B C L$} \\
\hline IPI $>2$ & 2.92 & $1.76-4.85$ & $<0.001$ & 2.04 & $1.49-3.88$ & $<0.001$ \\
\hline B-symptoms & 1.25 & $0.75-2.11$ & 0.40 & 1.23 & $0.75-2.04$ & 0.41 \\
\hline Tumor size $\geq 5 \mathrm{~cm}$ & 1.11 & $0.68-1.82$ & 0.68 & 1.06 & $0.66-1.69$ & 0.82 \\
\hline Female sex & 1.04 & $0.62-1.73$ & 0.88 & 1.09 & $0.67-1.77$ & 0.74 \\
\hline TP53 mutation & 2.08 & $1.14-3.79$ & 0.017 & 1.84 & $1.03-3.29$ & 0.039 \\
\hline Myc ${ }^{\text {high }}$ & 1.63 & $1.03-2.60$ & 0.038 & 1.61 & $1.01-2.58$ & 0.046 \\
\hline Bcl- $2^{\text {high }}$ & 2.92 & $1.76-4.85$ & 0.006 & 1.94 & $1.19-3.17$ & 0.008 \\
\hline p50 $0^{+}$ & 1.77 & $1.11-2.82$ & 0.016 & 1.59 & $1.02-2.48$ & 0.042 \\
\hline \multicolumn{7}{|l|}{ In WT-TP53 DLBCL } \\
\hline IPI $>2$ & 2.33 & $1.51-3.58$ & $<0.001$ & 2.11 & $1.40-3.18$ & $<0.001$ \\
\hline B-symptoms & 1.71 & $1.09-2.67$ & 0.019 & 1.65 & $1.07-2.50$ & 0.023 \\
\hline Tumor size $\geq 5 \mathrm{~cm}$ & 1.17 & $0.75-1.80$ & 0.49 & 1.08 & $0.71-1.63$ & 0.73 \\
\hline Female sex & 0.86 & $0.55-1.34$ & 0.50 & 0.88 & $0.57-1.34$ & 0.55 \\
\hline Mychigh & 2.10 & $1.36-3.24$ & 0.001 & 2.08 & $1.38-3.13$ & $<\mathbf{0 . 0 0 1}$ \\
\hline Bcl- $2^{\text {high }}$ & 1.65 & $1.05-2.58$ & 0.029 & 1.54 & $1.01-2.34$ & 0.043 \\
\hline p50 & 1.91 & $1.25-2.93$ & 0.003 & 1.68 & $1.11-2.52$ & 0.012 \\
\hline \multicolumn{7}{|l|}{ In MUT-TP53 DLBCL } \\
\hline IPI $>2$ & 2.38 & $1.20-4.74$ & 0.013 & 2.70 & $1.46-4.98$ & 0.002 \\
\hline B-symptoms & 1.90 & $0.87-4.15$ & 0.11 & 1.36 & $0.65-2.87$ & 0.41 \\
\hline Tumor size $\geq 5 \mathrm{~cm}$ & 1.42 & $0.65-3.07$ & 0.38 & 1.78 & $0.84-3.78$ & 0.13 \\
\hline Female sex & 0.52 & $0.25-1.08$ & 0.08 & 0.64 & $0.32-1.28$ & 0.21 \\
\hline Mychigh & 2.78 & $1.35-5.72$ & 0.005 & 2.14 & $1.10-4.18$ & 0.026 \\
\hline Bcl-2 ${ }^{\text {high }}$ & 2.09 & $1.06-4.12$ & 0.033 & $\begin{array}{l}2.14 \\
1.97\end{array}$ & $1.01-3.88$ & 0.048 \\
\hline p50 & 0.52 & $0.20-1.32$ & 0.17 & 0.56 & $0.24-1.30$ & 0.18 \\
\hline \multicolumn{7}{|c|}{ In WT-TP53 GCB-DLBCL } \\
\hline IPI $>2$ & 4.07 & $1.83-9.06$ & 0.001 & 4.98 & $2.37-10.5$ & $<0.001$ \\
\hline B-symptoms & 1.52 & $0.67-3.47$ & 0.32 & 1.43 & $0.66-3.13$ & 0.37 \\
\hline Tumor size $\geq 5 \mathrm{~cm}$ & 1.53 & $0.67-3.49$ & 0.31 & 1.58 & $0.73-3.44$ & 0.25 \\
\hline Female sex & 0.72 & $0.32-1.63$ & 0.43 & 0.75 & $0.35-1.59$ & 0.45 \\
\hline Mychigh & 2.52 & $1.06-6.03$ & $<0.001$ & 2.27 & $1.04-4.98$ & 0.04 \\
\hline Bcl- $2^{\text {high }}$ & 1.38 & $0.57-3.36$ & 0.48 & 1.44 & $0.64-3.26$ & 0.38 \\
\hline p50 $0^{+}$ & 2.19 & $1.02-4.68$ & 0.044 & 1.66 & $0.75-3.66$ & 0.21 \\
\hline \multicolumn{7}{|c|}{ In MUT-TP53 GCB-DLBCL } \\
\hline IPI $>2$ & 1.03 & $0.41-2.61$ & 0.95 & 1.32 & $0.58-3.01$ & 0.51 \\
\hline B-symptoms & 1.99 & $0.70-5.64$ & 0.20 & 1.37 & $0.53-3.56$ & 0.52 \\
\hline Tumor size $\geq 5 \mathrm{~cm}$ & 0.84 & $0.29-2.47$ & 0.75 & 1.16 & $0.46-2.94$ & 0.75 \\
\hline Female sex & 0.37 & $0.14-0.97$ & 0.044 & 0.42 & $0.17-1.03$ & 0.057 \\
\hline Mychigh & 6.39 & $2.45-16.7$ & $<0.001$ & 2.93 & $1.30-6.57$ & 0.009 \\
\hline Bcl-2 high & 2.23 & $0.81-6.13$ & 0.12 & 2.21 & $0.93-5.29$ & 0.074 \\
\hline p50 $0^{+}$ & 0.087 & $0.011-0.67$ & 0.019 & 0.46 & $0.41-1.50$ & 0.20 \\
\hline \multicolumn{7}{|c|}{ In WT-TP53 ABC-DLBCL } \\
\hline IPI $>2$ & 2.58 & $1.50-4.44$ & 0.001 & 2. 02 & $1.24-3.30$ & 0.005 \\
\hline B-symptoms & 1.49 & $0.84-2.67$ & 0.17 & 1.43 & $0.53-2.47$ & 0.20 \\
\hline Tumor size $\geq 5 \mathrm{~cm}$ & 0.96 & $0.56-1.67$ & 0.89 & 0.92 & $0.55-1.53$ & 0.74 \\
\hline Female sex & 1.00 & $0.57-1.74$ & 0.99 & 1.02 & $0.60-1.74$ & 0.94 \\
\hline Mychigh $^{\text {high }}$ & 2.08 & $1.21-3.58$ & 0.008 & 1.96 & $1.18-3.27$ & 0.01 \\
\hline Bcl- $2^{\text {high }}$ & 2.44 & $1.28-4.63$ & 0.006 & 2.00 & $1.12-3.57$ & 0.02 \\
\hline p50 & 1.97 & $1.16-3.35$ & 0.012 & 1.74 & $1.05-2.87$ & 0.03 \\
\hline
\end{tabular}




\begin{tabular}{|c|c|c|c|c|c|c|}
\hline & \multicolumn{3}{|c|}{ OS } & \multicolumn{3}{|c|}{ PFS } \\
\hline & $H R$ & $95 \% C I$ & $\mathrm{P}$ & $H R$ & $95 \% C I$ & $\mathrm{P}$ \\
\hline \multicolumn{7}{|c|}{ In MUT-TP53 ABC-DLBCL } \\
\hline IPI $>2$ & 16.5 & $3.17-85.4$ & 0.001 & 13.8 & $3.10-61.8$ & 0.001 \\
\hline B-symptoms & 1.01 & $0.29-3.47$ & 0.99 & 0.84 & $0.25-2.89$ & 0.78 \\
\hline Tumor size $\geq 5 \mathrm{~cm}$ & 2.19 & $0.57-8.36$ & 0.25 & 2.55 & $0.65-10.0$ & 0.18 \\
\hline Female sex & 1.37 & $0.40-4.64$ & 0.62 & 1.86 & $0.58-6.03$ & 0.30 \\
\hline Myc high & 0.40 & $0.10-1.60$ & 0.20 & 0.47 & $0.13-1.69$ & 0.25 \\
\hline Bcl-2high & 0.56 & $0.16-2.00$ & 0.37 & 0.77 & $0.22-2.72$ & 0.69 \\
\hline p50 $0^{+}$ & 3.41 & $0.74-15.7$ & 0.11 & 2.28 & $0.55-9.44$ & 0.26 \\
\hline
\end{tabular}

Abbraviations: ABC, activated B-cell-like; CI, confidence interval; GCB, germinal center B-cell-like; HR, hazard ratio; IPI, International Prognostic Index; MUT-TP53, mutated TP5; OS, overall survival; PFS, progression-free survival; R-CHOP, rituximab with cyclophosphamide, doxorubicin, vincristine, and prednisone; WT-TP53, wild-type TP53.

Cutoffs for Myc high, Bcl- $2^{\text {high }}$, and $\mathrm{p}^{\text {h }} 0^{+}$are $\geq 70 \%, \geq 70 \%$, and $\geq 20 \%$, respectively.

Bold values are statistically significant.

suggesting negative regulation of adaptive and innate immune responses in $\mathrm{p}^{+} 0^{+}$patients. HAVCR2/TIM3, which inhibits T-helper 1 (Th1)-mediated immune responses by inducing Th1 apoptosis upon ligation, ${ }^{29}$ had 1.45 -fold upregulation in $\mathrm{p}^{+} 0^{+}$diffuse large B-cell lymphoma (vs p50- diffuse large B-cell lymphoma), 1.57-fold upregulation in $\mathrm{p} 50^{+}$germinal center B-cell-like diffuse large B-cell lymphoma (vs

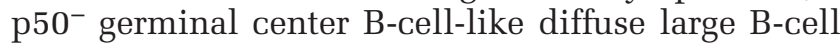
lymphoma) and 1.51-fold upregulation in $\mathrm{p}^{+} 0^{+}$ activated B-cell-like diffuse large B-cell lymphoma (vs $\mathrm{p}^{-} 0^{-}$activated B-cell-like diffuse large B-cell lymphoma). CD163, which encodes a marker for M2 macrophages, ${ }^{30}$ had 1.74-fold upregulation in $\mathrm{p}^{+} 0^{+}$ diffuse large B-cell lymphoma. SERPING1, which inhibits $\mathrm{C} 1$ complex in complement activation, ${ }^{31}$ had 1.45-fold upregulation in $\mathrm{p}^{+} 0^{+}$germinal center B-cell-like diffuse large B-cell lymphoma and 1.42fold upregulation in ${\mathrm{p} 50^{+}}^{+}$activated B-cell-like diffuse large B-cell lymphoma. LILRB2 and LILRB4, which encode leukocyte immunoglobulin-like receptors for major histocompatibility complex (MHC) class-I antigens on antigen-presenting cells downregulating T-cell response and innate immune response, ${ }^{32}$ had 1.78-fold upregulation in ${\mathrm{p} 50^{+}}^{+}$ diffuse large B-cell lymphoma and 1.43-fold upregu-

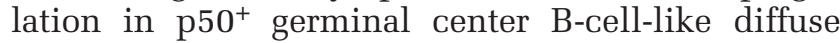
large B-cell lymphoma, respectively. SLAMF7, which has inhibitory effects on the production of pro-inflammatory cytokines by monocytes, ${ }^{33}$ had 2.06-fold upregulation in ${\mathrm{p} 50^{+}}^{+}$diffuse large B-cell lymphoma and 1.75-fold upregulation in ${\mathrm{p} 50^{+}}^{+}$ activated B-cell-like diffuse large B-cell lymphoma. In addition, LST1, which inhibits lymphocyte proliferation, ${ }^{34}$ had 1.40 -fold upregulation in $\mathrm{p} 50^{+}$ activated B-cell-like diffuse large B-cell lymphoma.

A few apoptosis genes showed significant differ-

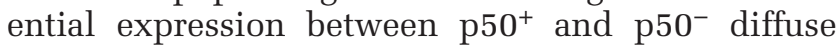
large B-cell lymphoma. PHLDA1, an apoptosis suppressor, was significantly upregulated in $\mathrm{p} 50^{+}$ germinal center B-cell-like diffuse large B-cell lymphoma. ${ }^{35}$ However, DAPK1, a tumor-suppressor candidate gene, and $X A F 1$, a p53 target gene that enhances p53-mediated apoptosis via posttranslational modification, ${ }^{36}$ were also significantly upregulated in ${\mathrm{p} 50^{+}}^{+}$germinal center B-cell-like diffuse large B-cell lymphoma and $\mathrm{p}^{+} 0^{+}$activated B-cell-like diffuse large B-cell lymphoma. In activated B-cell-like diffuse large B-cell lymphoma, EPB41L3, encoding the tumor-suppressor DAL-1/4.1B, which inhibits proliferation and promotes apoptosis, was upregulated, ${ }^{37}$ whereas FOXP1 that cooperates with NF- $\kappa$ B signaling to promote B-cell growth and survival ${ }^{38}$ was significantly downregulated (consistent with the negative correlation at the protein level, Table 1) in the p50 $0^{+}$group.

As $\mathrm{p}^{+} 0^{+}$status correlated with opposite prognostic effects in patients with WT-TP53 and in those with MUT-TP53, we compared gene expression profiling between ${\mathrm{p} 50^{+}}^{+}$and ${\mathrm{p} 50^{-}}^{-}$diffuse large B-cell lymphoma in the WT-TP53 and MUT-TP53 subcohorts individually. With a false discovery rate cutoff of $0.01,399$ and 54 significant transcripts were identified between $\mathrm{p}^{+} 0^{+}$and $\mathrm{p} 50^{-}$patients in the WT-TP53 and MUT-TP53 subcohorts, respectively (Table 3). These two sets of ${\mathrm{p} 50^{+}}^{+}$gene signatures resembled each other including upregulation of immune and proapoptotic genes. Common genes shared by the p50 ${ }^{+}$WT-TP53 and p50 $0^{+}$MUT-TP53 gene signatures are shown in Table 3 . When analyzed in the germinal center B-cell-like and activated B-cell-like subcohorts of WT-TP53/MUT-TP53 diffuse large B-cell lymphoma, distinct p50 gene expression signatures were identified only in the MUT-TP53 germinal center B-cell-like and WT-TP53 activated B-cell-like diffuse large B-cell lymphoma subsets (Figure 6c-f) but not in the WT-TP53 germinal center B-cell-like and MUT-TP53 activated B-cell-like subsets (although with a high false discovery rate threshold of 0.30 , there were 15 genes differentially expressed between $\mathrm{p} 50^{+}$and $\mathrm{p} 50^{-}$patients in the WT-TP53 germinal center B-cell-like subset). Notably, upregulation of immunosuppressive LILRA2 in $\mathrm{p} 50^{+}$patients was significant in the WT-TP53 diffuse 
Table 3 Differentially expressed genes between $\mathrm{p}^{+} 0^{+}$and ${\mathrm{p} 50^{-}}^{-}$patients with de novo diffuse large B-cell lymphoma (DLBCL) in the overall diffuse large B-cell lymphoma study cohort, and in the diffuse large B-cell lymphoma subcohorts with germinal center B-cell-like subtype, activated B-cell-like subtype, wild-type TP53, or mutated TP53

\begin{tabular}{|c|c|c|c|c|c|c|c|}
\hline \multirow{2}{*}{ Function categories } & \multicolumn{6}{|c|}{$p 50^{+}$vs $p 50^{-}$} & \multirow[b]{2}{*}{$\begin{array}{l}\text { MUT-TP53 p50 } \\
\text { GCB Vs WT-TP53 } p^{+} 0^{+} A B C \\
\text { FDR }<0.20\end{array}$} \\
\hline & $\begin{array}{l}\text { In overall DLBCL ( }>1.74 \text {-fold) } \\
F D R<0.01\end{array}$ & $\begin{array}{l}\text { In GCB-DLBCL } \\
F D R<0.01\end{array}$ & $\begin{array}{l}\text { In } A B C-D L B C L(>1.5-\text { fold }) \\
F D R<0.01\end{array}$ & $\begin{array}{l}\text { In WT-TP53 ( }>1.4 \text {-fold }) \\
F D R<0.01\end{array}$ & $\begin{array}{l}\text { In } M U T-T P 53 \\
F D R<0.01\end{array}$ & $\begin{array}{l}\text { In MUT-TP53 GCB-DLBCL } \\
F D R<0.05\end{array}$ & \\
\hline Signaling, ion-channel & 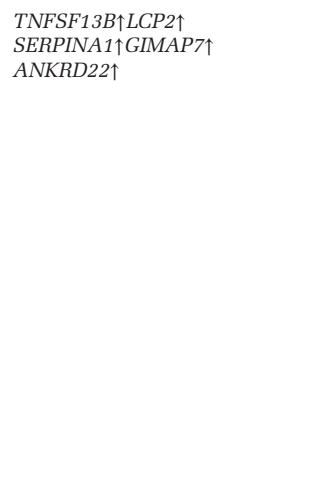 & 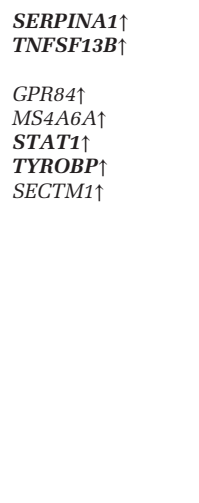 & 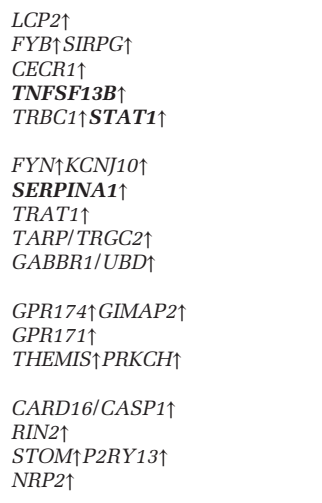 & 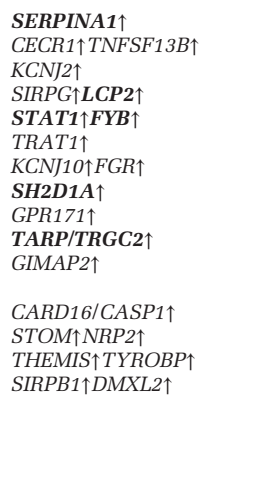 & 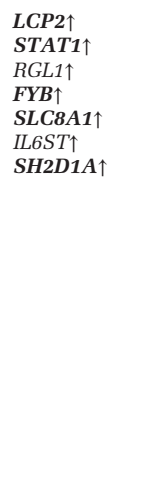 & 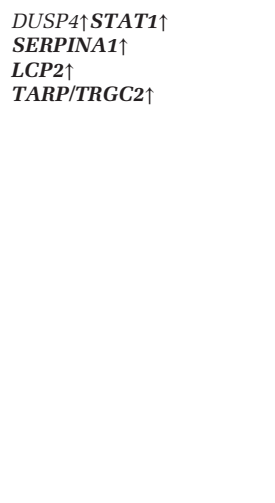 & 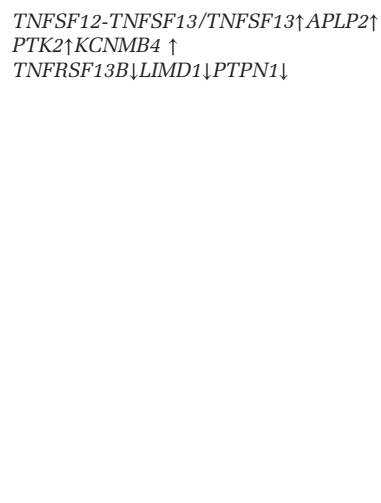 \\
\hline $\begin{array}{l}\text { Transcription regulation, } \\
\text { translation, DNA metabolism }\end{array}$ & 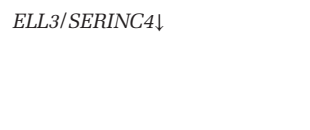 & $A S C L 2 \uparrow$ & $\begin{array}{l}B C L 11 B \uparrow M A F \uparrow \\
T X N I P \uparrow \\
T F E C \uparrow I R F 1 \uparrow \\
T F E C \uparrow \\
B C L 11 A \downarrow F O X P 1 \downarrow\end{array}$ & 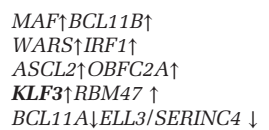 & $\begin{array}{l}E I F 4 E 3 \uparrow \\
N R 1 H 3 \uparrow \\
M A F B \uparrow \\
\text { GINS3 } \downarrow\end{array}$ & $K L F 3 \uparrow Q K I \uparrow$ & $\begin{array}{l}\text { AFF2 } \\
\text { CHD } 1 \downarrow P A R P 15 \downarrow\end{array}$ \\
\hline $\begin{array}{l}\text { Immune response, } \\
\text { inflammation, cytokines }\end{array}$ & 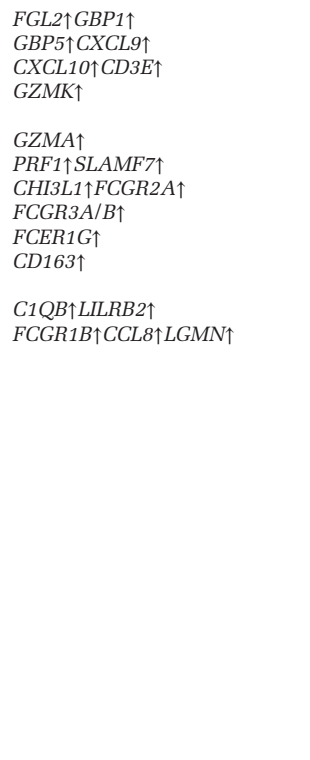 & 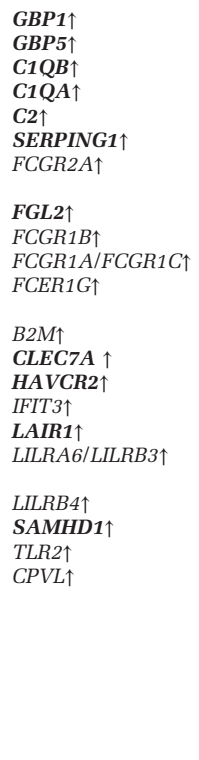 & 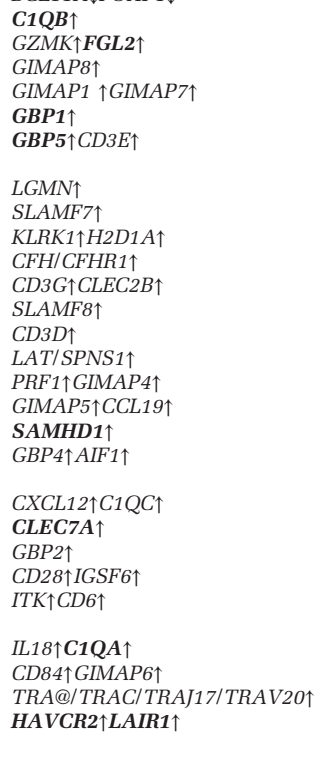 & 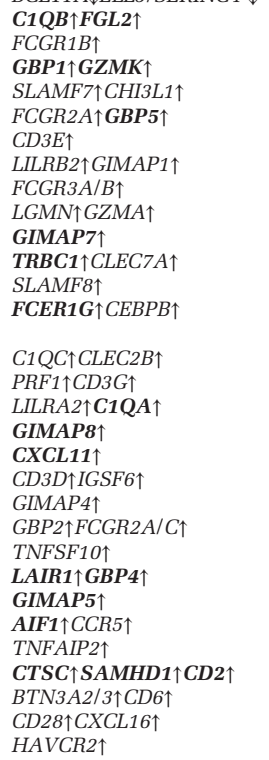 & 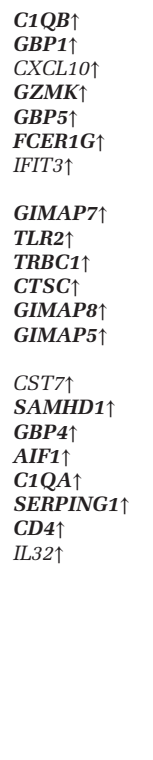 & 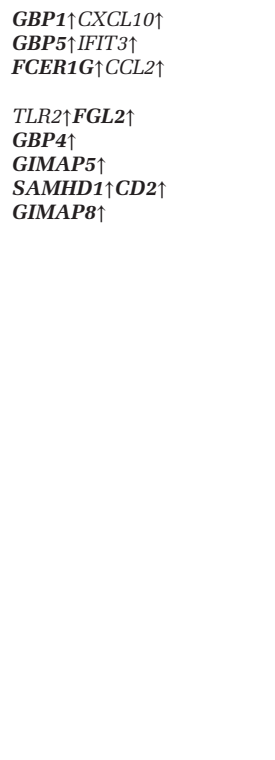 & \\
\hline
\end{tabular}


Table 3 (Continued)

\begin{tabular}{|c|c|c|c|c|c|c|c|}
\hline \multirow{2}{*}{ Function categories } & \multicolumn{6}{|c|}{$p 50^{+}$vs $p 50^{-}$} & \multirow[b]{2}{*}{$\begin{array}{l}\text { MUT-TP53 } p 50^{+} \\
\text {GCB vs WT-TP53 } p 50^{+} A B C \\
F D R<0.20\end{array}$} \\
\hline & $\begin{array}{l}\text { In overall DLBCL ( }>1.74 \text {-fold) } \\
F D R<0.01\end{array}$ & $\begin{array}{l}\text { In } G C B-D L B C L \\
F D R<0.01\end{array}$ & $\begin{array}{l}\text { In } A B C-D L B C L \text { ( }>1.5 \text {-fold }) \\
F D R<0.01\end{array}$ & $\begin{array}{l}\text { In WT-TP53 (>1.4-fold) } \\
F D R<0.01\end{array}$ & $\begin{array}{l}\text { In MUT-TP53 } \\
F D R<0.01\end{array}$ & $\begin{array}{l}\text { In MUT-TP53 GCB-DLBCL } \\
F D R<0.05\end{array}$ & \\
\hline $\begin{array}{l}\text { Lysosome, degradation, chaperon, } \\
\text { protein folding, transport, trafficking }\end{array}$ & $C T S B \uparrow$ & $\begin{array}{l}\text { CTSB } \uparrow \\
\text { SCARB2 } 2 \\
\text { VAMP } 5 \uparrow\end{array}$ & $\begin{array}{l}A P O L 6 \uparrow \\
R T N 1 \uparrow \\
D A B 2 \uparrow \\
C T S B \uparrow \\
P S A P \uparrow \\
L Y S T \uparrow\end{array}$ & $\begin{array}{l}L Y Z \uparrow \\
C T S B \uparrow L A M P 2 \uparrow \\
A P O L 6 \uparrow P S A P \uparrow \\
R N F 213 \uparrow P D I A 3 \downarrow\end{array}$ & $\begin{array}{l}C S T B \uparrow \\
V A M P 5 \uparrow \\
A R L C C \uparrow \\
P R C P \uparrow\end{array}$ & $\begin{array}{l}\text { APOL6 } \uparrow \\
\text { VAMP5 } \uparrow \\
\text { ARL4C } \uparrow \\
P R C P \uparrow R T N 1 \uparrow\end{array}$ & \\
\hline Apoptosis, autophagy & & $\begin{array}{l}\text { XAF1 } \uparrow \\
\text { DAPK1 } \uparrow \\
P H L D A 1 \uparrow\end{array}$ & $\begin{array}{l}\text { XAF1 } \uparrow \\
\text { DAPK1 } \uparrow \\
E P B 41 L 3 \uparrow\end{array}$ & $\begin{array}{l}\mathbf{X A F 1 \uparrow} \\
D A P K 1 \uparrow \\
E P B 41 L 3 \uparrow \\
R A S S F 4 \uparrow \\
\\
F N I P 2 \uparrow\end{array}$ & 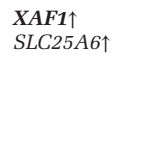 & $\begin{array}{l}\text { XAF1 } \uparrow \\
T R I M 69 \uparrow\end{array}$ & $U L K 3 \downarrow$ \\
\hline $\begin{array}{l}\text { Membrane, adhesion, cytoskeleton, } \\
\text { extracellular matrix, angiogenesis }\end{array}$ & & $M Y O F \uparrow$ & $\begin{array}{l}A N X A 4 \uparrow \\
E M R 2 \uparrow \\
U T R N \uparrow \\
T I M P 2 \uparrow\end{array}$ & 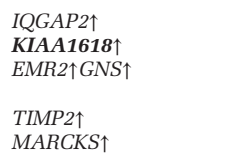 & $\begin{array}{l}\text { MYOF } \uparrow \\
\text { PVRL } 2 \uparrow\end{array}$ & 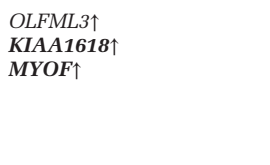 & $\begin{array}{l}L T B P 1 \uparrow \\
D N M 2 \downarrow\end{array}$ \\
\hline Metabolism, homeostasis & SERINC4 $\downarrow$ & 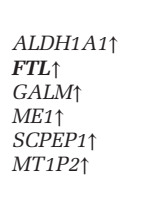 & $\begin{array}{l}H N M T \uparrow \\
T B C 1 D 4 \uparrow \\
A P O C 1 \uparrow \\
H S 3 S T 3 B 1 \uparrow \\
M G A T 4 A \uparrow \\
N P L \uparrow \\
G L S \uparrow\end{array}$ & 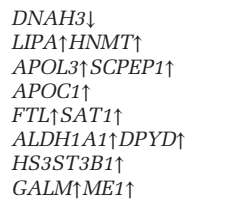 & $A P O L 2 \uparrow$ & 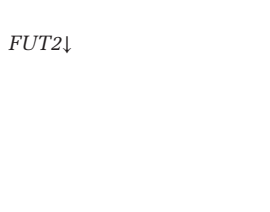 & $S L C 25 A 27 \uparrow$ \\
\hline Differentiation, development & & 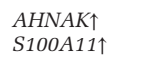 & $\begin{array}{l}\text { GPRIN } 3 \uparrow C P M \uparrow \\
I T M 2 A \uparrow S L F N 5 \uparrow\end{array}$ & $P R D M 1 \uparrow C P M \uparrow$ & & & \\
\hline Others, unknown function & FAM 26 F & C10orf128 $\uparrow$ & 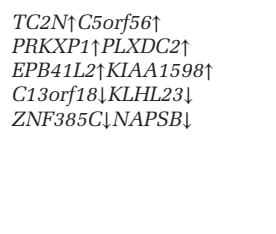 & 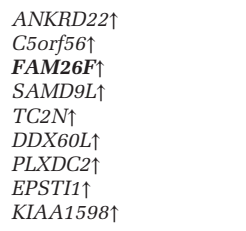 & 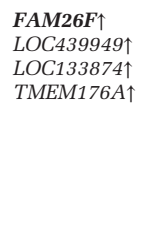 & 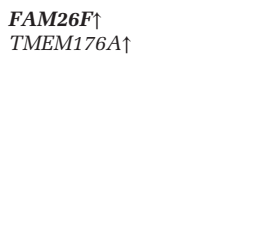 & 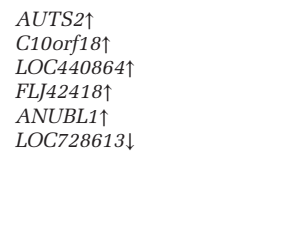 \\
\hline
\end{tabular}

Abbreviations: ABC, activated B-cell-like; FDR, false discovery rate; GCB, germinal center B-cell-like; MUT-TP53, mutated TP53; WT-TP53, wild-type TP53.

Genes in bold are common genes between p50 GCB-DLBCL signatures and p50 $0^{+}$ABC-DLBCL signatures (without cutoff for fold changes; FDR $<0.01$ ), those between p50 $0^{+}$WT-TP53 DLBCL signatures(without cutoff for fold changes) and p50 ${ }^{+}$MUT-TP53 DLBCL signatures (FDR $<0.01$ ), and those between p50 ${ }^{+}$WT-TP53 ABC-DLBCL signatures (FDR $<0.01$ ) and p50 $0^{+}$MUT-TP53 GCBDLBCL signatures (FDR <0.05). 

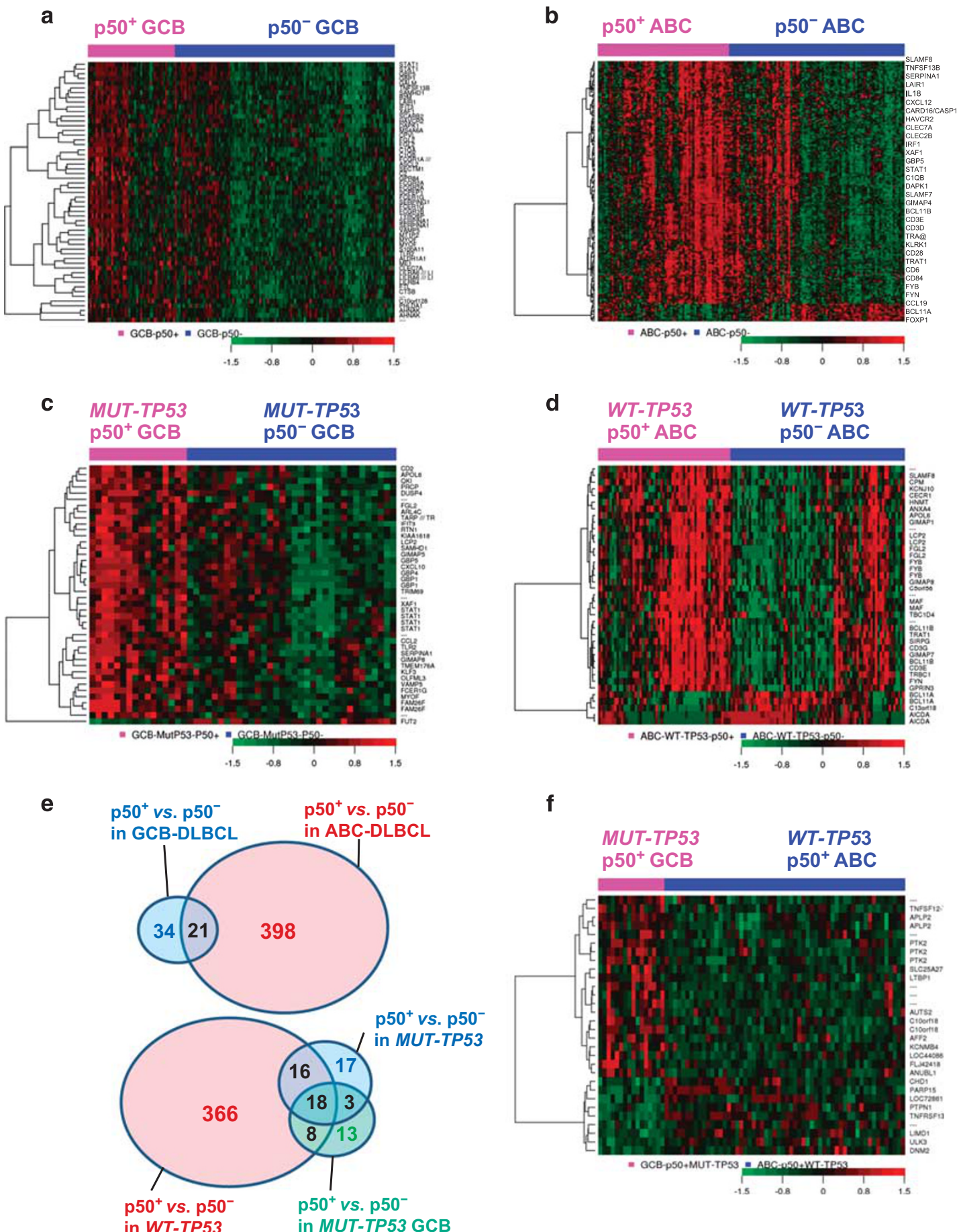

Figure 6 Gene expression profiling (GEP) analysis for p50 nuclear expression in diffuse large B-cell lymphoma (DLBCL). (a) Significantly differentially expressed genes between $\mathrm{p}^{+} 0^{+}$and $\mathrm{p}^{-} 0^{-}$germinal center B-cell-like (GCB) diffuse large B-cell lymphoma (false discovery rate $<0.01$ ). (b) Significantly differentially expressed genes between p50 ${ }^{+}$and p50- activated B-cell-like (ABC) diffuse large B-cell lymphoma with $>1.50$-fold difference (false discovery rate $<0.01$ ). (c) Significantly differentially expressed genes between p50 $0^{+}$and p50- germinal center B-cell-like diffuse large B-cell lymphoma patients with mutated TP53 (MUT-TP53; false discovery rate <0.05).

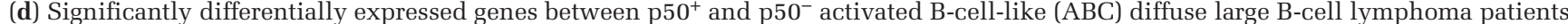
with wild-type TP53 (WT-TP53; false discovery rate <0.01). (e) Venn diagrams illustrating the overlap of p50 ${ }^{+}$germinal center B-cell-like diffuse large B-cell lymphoma gene signatures (blue circle) and $\mathrm{p}^{+} 0^{+}$activated B-cell-like diffuse large B-cell lymphoma gene signatures (red circle), and the overlap of p50 ${ }^{+}$WT-TP53 diffuse large B-cell lymphoma gene signatures (red circle), p50 ${ }^{+}$MUT-TP53 diffuse large B-cell lymphoma gene signatures (blue circle), and p50+ $M U T$-TP53 germinal center B-cell-like diffuse large B-cell lymphoma gene signatures. (f) Significantly differentially expressed genes between the p50 ${ }^{+}$germinal center B-cell-like diffuse large B-cell lymphoma patients with mutated TP53 and the p50 activated B-cell-like diffuse large B-cell lymphoma patients with wild-type TP53 (false discovery rate $<0.20)$. 

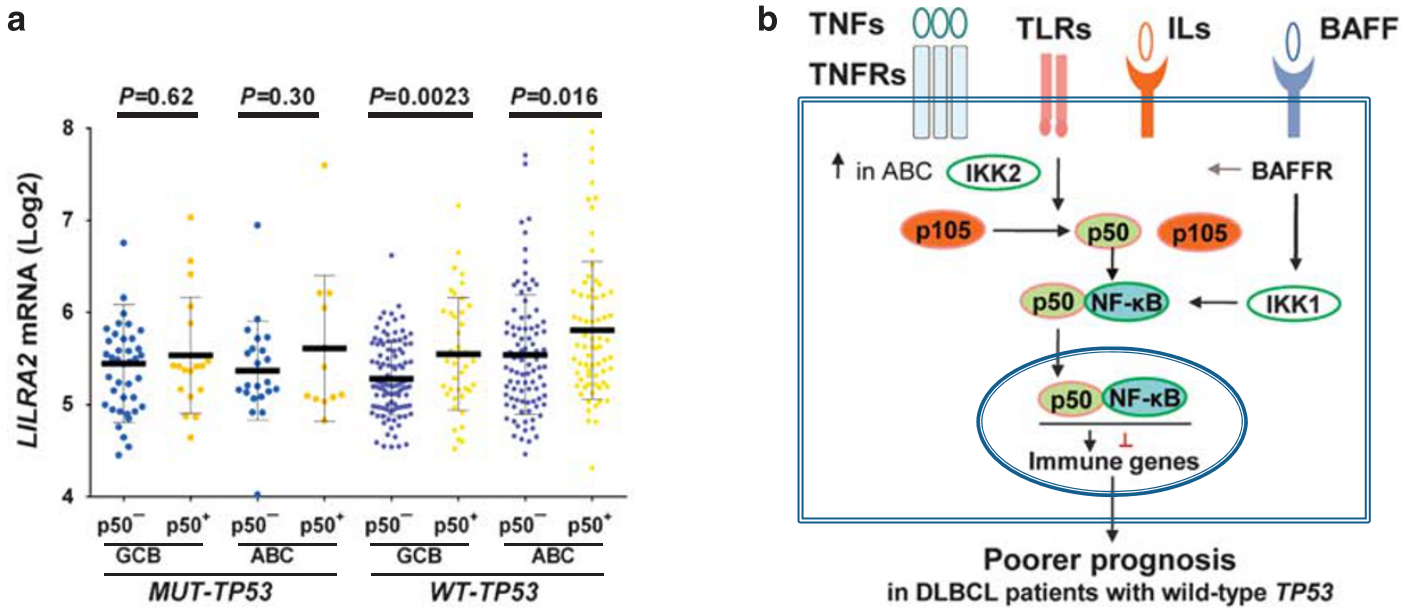

in DLBCL patients with wild-type TP53
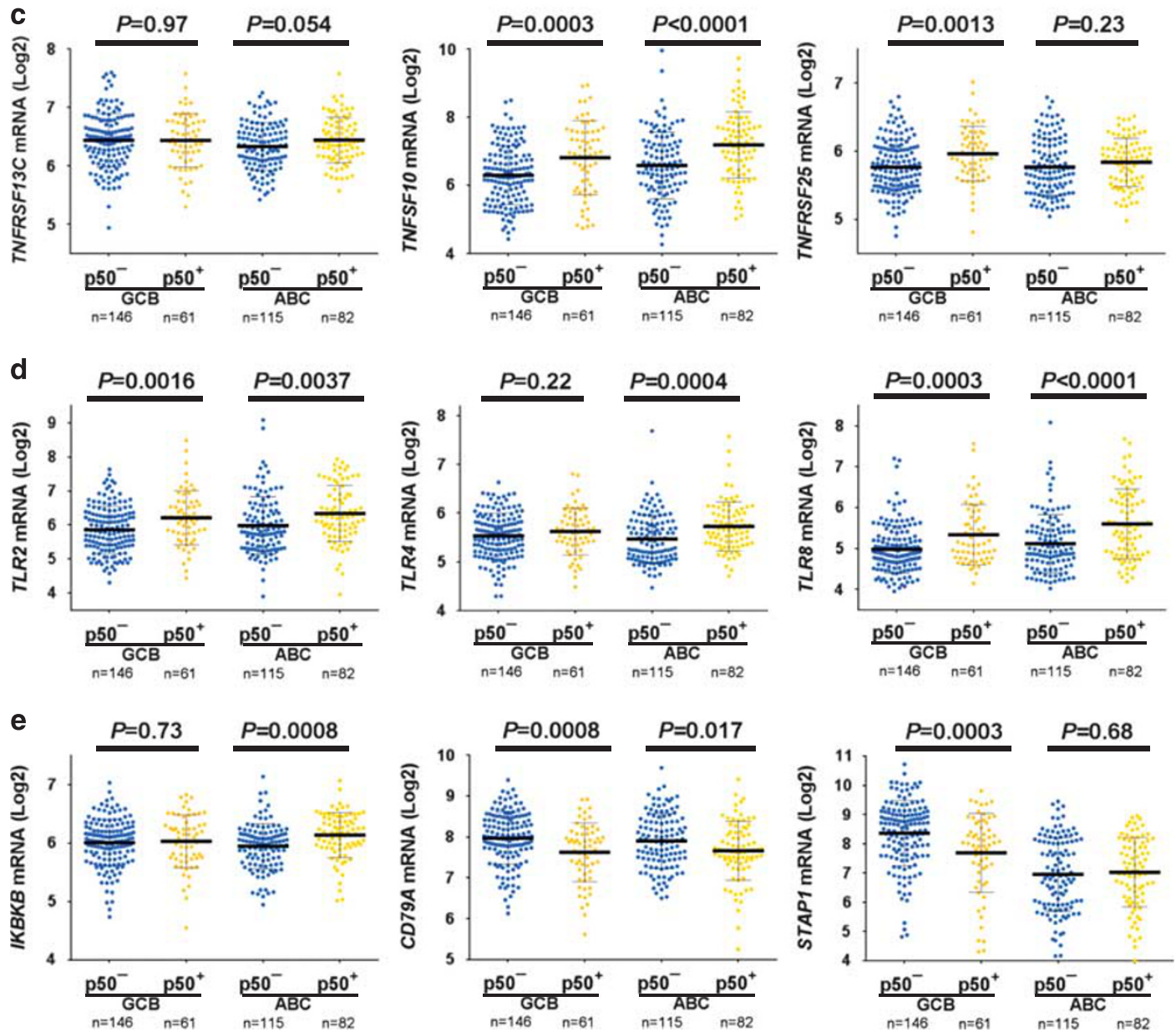

Figure 7 Correlations between p50 nuclear expression and upstream signaling genes in diffuse large B-cell lymphoma (DLBCL). (a) The

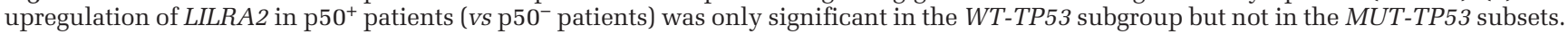
(b) A schematic summary illustrating multiple NF- $\kappa \mathrm{B}$ activating signaling pathways and the potential link to the poorer prognosis associated with p50 activation in diffuse large B-cell lymphoma patients with WT-TP53. BAFF, B-cell-activating factor; BAFFR, BAFF receptor; IKK, inhibitor of nuclear factor-kappa-B kinase; ILs, interleukins; TLRs, Toll-like receptors; TNFs/TNFRs, tumor necrosis factor ligands/receptors. (c) p50 status was associated with increased TNFRSF13C/BAFFR expression in activated B-cell-like (ABC) diffuse large B-cell lymphoma, significant upregulation of TNFRSF25 in germinal center B-cell-like (GCB) diffuse large B-cell lymphoma, and significant upregulation of TNFSF10 in both germinal center B-cell-like and activated B-cell-like diffuse large B-cell lymphoma. (d) p50 ${ }^{+}$ status was associated with significant upregulation of Toll-like receptors (TLRs) in diffuse large B-cell lymphoma. (e) p50 ${ }^{+}$status was associated with significant upregulation of $I K B K B / I K K 2$ in activated B-cell-like diffuse large B-cell lymphoma, and significant downregulation of CD79A and STAP1 in germinal center B-cell-like diffuse large B-cell lymphoma. 
large B-cell lymphoma but not in the MUT-TP53 diffuse large B-cell lymphoma subset (Figure 7a), in which $\mathrm{p} 0^{+}$status predicted poorer survival. On the other hand, essentially all the $\mathrm{p}^{+} 0^{+}$gene signatures except FUT2 (fucosyltransferase 2) identified in the MUT-TP53 germinal center B-cell-like diffuse large B-cell lymphoma subset (in which ${\mathrm{p} 50^{+}}^{+}$status predicted better survival) were also significantly differentially expressed between $\mathrm{p}^{+} 0^{+}$and $\mathrm{p} 50^{-}$ patients in WT-TP53 diffuse large B-cell lymphoma $(P<0.05)$, leaving little explanations for the different prognostic impact. Gene expression profiling of the p50 $^{+}$WT-TP53 activated B-cell-like diffuse large B-cell lymphoma and the $5^{+} 0^{+}$MUT-TP53 germinal center B-cell-like diffuse large B-cell lymphoma groups was further compared, which resulted in 30 significant transcripts with a false discovery rate $<0.20$ (Figure 6f, Table 3). Expression of APLP2 (which encodes amyloid precursor-like protein 2 associated with MHC class 1 molecules), PTK2 (which encodes protein tyrosine kinase 2), and LTBP1 (latent TGF-beta binding protein 1, which regulates the secretion and activation of TGF-beta) was significantly higher in the p50 ${ }^{+}$MUT-TP53 germinal center B-cell-like diffuse large B-cell lymphoma group, whereas expression of TNFRSF13B (TACI), PARP15 (encoding a transcriptional repressor), and ULK3 (involved in autophagy) was significantly higher in the ${\mathrm{p} 50^{+} W T-T P 53}$ activated B-cell-like diffuse large B-cell lymphoma group.

\section{Tumor Necrosis Factor- and Toll-Like Receptor- Involved Signaling Pathways may Have Important Roles in the p50 Activation}

We further examined the upstream signaling that potentially activated p50 via either the canonical or noncanonical NF- $\kappa \mathrm{B}$ pathways. A brief schematic summary of these potential signaling cascades and their prognostic impact for patients with WT-TP53 is shown in Figure 7b.

TNFSF13B, which encodes the B-cell-activating factor $B A F F$ involved in noncanonical activation of $\mathrm{NF}-\kappa \mathrm{B},{ }^{39}$ was upregulated in $\mathrm{p}^{+} 0^{+}$patients in the
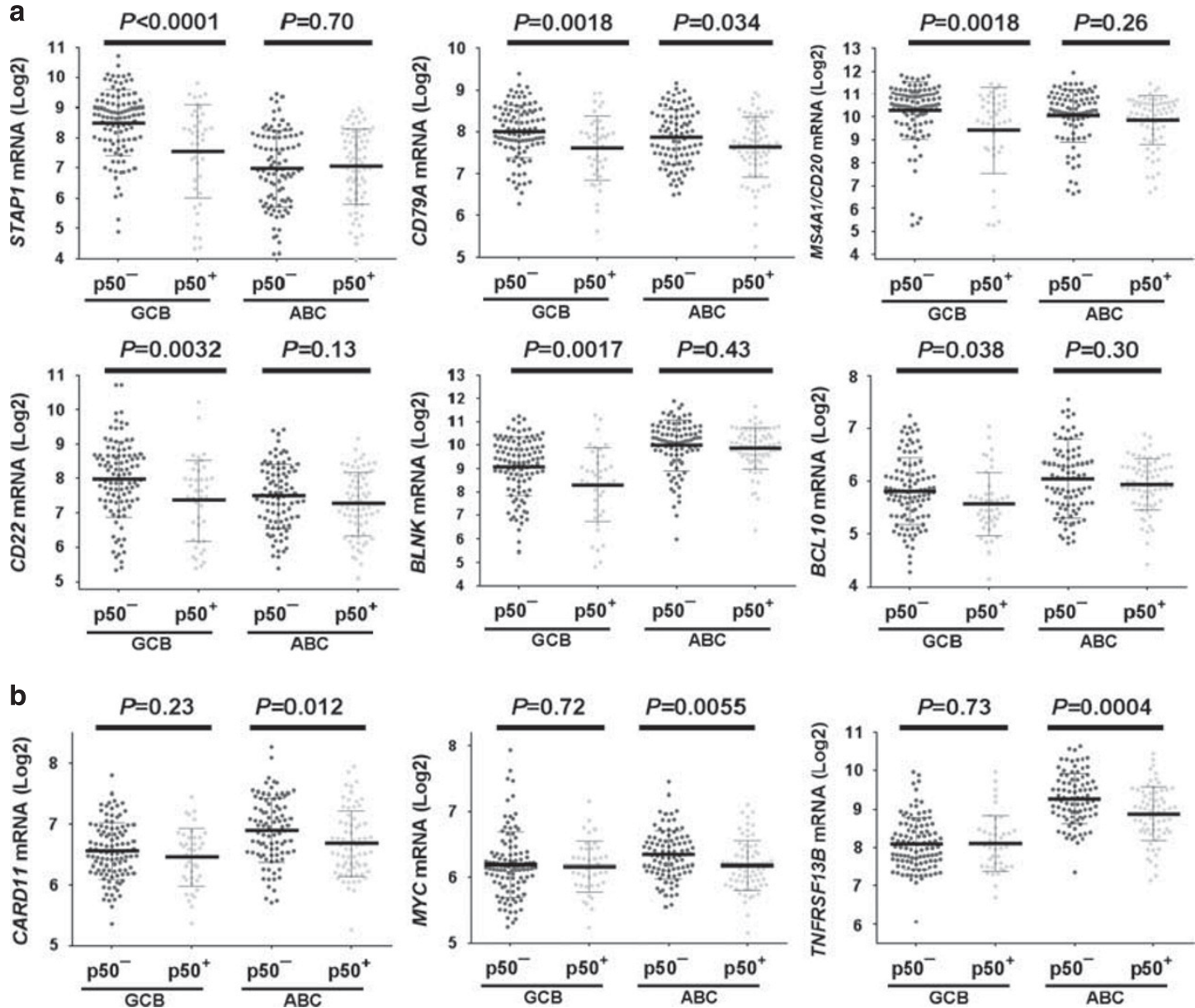

Figure 8 Correlations between p50 nuclear expression and upstream signaling genes in diffuse large B-cell lymphoma (DLBCL) with wildtype TP53 (WT-TP53). (a) In the germinal center B-cell-like (GCB) subtype, p50 ${ }^{+}$status significantly correlated with downregulation of STAP1, CD79A, CD20, CD22, BLNK, and BCL10. (b) In the activated B-cell-like (ABC) subtype, p50 ${ }^{+}$status correlated with downregulation of CARD11, MYC, and TNFRSF13B significantly. 
overall diffuse large B-cell lymphoma, germinal center B-cell-like diffuse large B-cell lymphoma, and activated B-cell-like diffuse large B-cell lymphoma cohorts (Table 3). TNFRSF13C, encoding the $\mathrm{BAFF}$ receptor BAFFR, which preferably activates the noncanonical NF- $\kappa$ B pathway, ${ }^{40}$ was upregulated only in $\mathrm{p}^{+} 0^{+}$activated B-cell-like diffuse large B-cell lymphoma with a borderline $P$-value (Figure 7c). Canonical pathway activation was suggested by upregulation of the Toll-like receptors TLR2/8 in germinal center B-cell-like diffuse large B-cell lymphoma and TLR1/2/4/8 in activated B-cell-like diffuse large B-cell lymphoma (Figure $7 \mathrm{~d}$ ); ${ }^{41}$ upregulation of $I K B K B / I K K 2$ (encoding $\mathrm{I} \kappa \mathrm{B}$ kinase $\beta$ ) in activated B-cell-like diffuse large B-cell lymphoma $(P=0.0008$, Figure 7e); upregulation of TNFRSF25 in germinal center B-cell-like diffuse large B-cell lymphoma; and upregulation of TNFSF10 in both germinal center B-cell-like and activated B-cell-like diffuse large B-cell lymphoma (Figure 7c). ${ }^{9}$ LCP2 and $F Y B$ involved in $\mathrm{T}$-cell antigen receptor signaling, and $S L A M F 8$ involved in lymphocyte activation through the B-cell receptor (BCR) signaling, were also upregulated in ${\mathrm{p} 50^{+}}^{+}$activated B-cell-like diffuse large B-cell lymphoma patients (Table 3). In contrast, several BCR signaling-related genes were downregulated in ${\mathrm{p} 50^{+}}^{+}$patients, including $C D 79 A, S T A P 1$ (Figure 7e), CD20, CD22, BLNK, and BCL10, which were downregulated in ${\mathrm{p} 50^{+}}^{+}$germinal center B-celllike diffuse large B-cell lymphoma $(P=0.0008$, $P=0.0003, P=0.0023, P=0.0036, P=0.0086$, and $P=0.023$, respectively), and CD79A, CARD11, TNFRSF13B (TACI), and MYC (consistent with the negative correlation at the protein level, Figure 4f), which were downregulated in $\mathrm{p}^{+} 0^{+}$activated B-celllike diffuse large B-cell lymphoma $(P=0.017$, $P=0.0033, P=0.0012$, and $P=0.0002$, respectively).

Further analysis in the WT-TP53 and MUT-TP53 subcohorts showed that downregulation of $C D 79 A$,

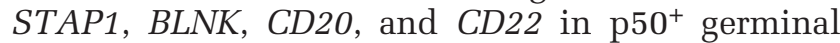
center B-cell-like diffuse large B-cell lymphoma and downregulation of TNFRSF13B (TACI) in ${\mathrm{p} 50^{+}}^{+}$ activated B-cell-like diffuse large B-cell lymphoma were restricted to the WT-TP53 patients (Figure 8a), whereas upregulation of TNFSF13B (BAFF), TLRs, TNFRSF25, TNFSF10, LCP2, FYB, and SLAMF8 were independent of WT-TP53 or MUT-TP53 status. Downregulation of $M Y C$ in ${\mathrm{p} 50^{+}}^{+}$activated B-celllike diffuse large B-cell lymphoma was also significant in both WT-TP53 $(P=0.0055$, Figure $8 \mathrm{~b})$ and MUT-TP53 $(P=0.0037)$ patients.

In addition, IL6ST involved in the IL6 signal pathway and IL32 encoding a cytokine that induces TNF-alpha and $\mathrm{IL}^{4}{ }^{42}$ were upregulated in ${ }^{2} 50^{+}$ MUT-TP53 patients (Table 3). IL18BP, which encodes an IL18 inhibitor that inhibits Th1 cytokine response $^{43}$ was upregulated in $\mathrm{p}^{+} 0^{+}$WT-TP53 diffuse large B-cell lymphoma, and IL18 was upregu-

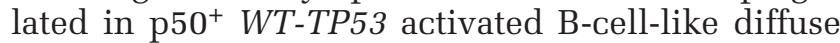
large B-cell lymphoma, which together might suggest the involvement of cytokine signaling pathways in $\mathrm{NF}-\kappa \mathrm{B}$ activation.

\section{Discussion}

Constitutive NF- $\kappa \mathrm{B}$ activation is a pathogenetic hallmark of activated B-cell-like diffuse large B-cell lymphoma. ${ }^{21}$ In the large cohort of diffuse large B-cell lymphoma presented here, p50 is the only NF$\kappa \mathrm{B}$ subunit (out of $5 \mathrm{NF}-\kappa \mathrm{B}$ subunits) that showed significantly higher mRNA (NFKB1) expression in activated B-cell-like diffuse large B-cell lymphoma than in germinal center B-cell-like diffuse large B-cell lymphoma, as well as a strong trend of increased nuclear protein (p50) expression (Figure 1c and d) and a significantly higher $\mathrm{p}^{+} 0^{+}$frequency (Table 1), ${ }^{21,44}$ suggesting its important role in mediating the oncogenic function of $\mathrm{NF}-\kappa \mathrm{B}$ in activated B-cell-like diffuse large B-cell lymphoma. Indeed, we showed that approximately one-third of the 465 studied diffuse large B-cell lymphoma patients had p50 activation as indicated by $\geq 20 \%$ positive nuclear expression. In addition, $\mathrm{p} 50^{+}$ nuclear expression was an independent adverse prognostic factor for patients with WT-TP53, and for patients with activated B-cell-like diffuse large B-cell lymphoma. These results, together with those from our earlier studies, ${ }^{21,44}$ show that both p50 and c-Rel are important for the poor prognosis of activated B-cell-like diffuse large B-cell lymphoma. However, in contrast to the poorer survival associated with elevated c-Rel levels in patients with MUT-TP53 activated B-cell-like diffuse large B-cell lymphoma, ${ }^{44}{\mathrm{p} 50^{+}}^{+}$nuclear expression correlated with significantly better survival in patients with MUT-TP53 germinal center B-cell-like diffuse large B-cell lymphoma and p50 levels were similar in WT-TP53 germinal center B-cell-like diffuse large B-cell lymphoma and MUT-TP53 germinal center B-cell-like diffuse large B-cell lymphoma $(P=0.87)$.

$\mathrm{p} 50^{+}$nuclear expression was found to be associated with p65, p52, and c-Rel nuclear expression in both the activated B-cell-like diffuse large B-cell lymphoma and WT-TP53 diffuse large B-cell lymphoma subgroups suggesting the potential NF- $\mathrm{NB}$ heterodimers. In comparison, $\mathrm{p} 50^{+}$nuclear expression was associated with p65 and p52 nuclear expression in germinal center B-cell-like diffuse large B-cell lymphoma, and none of the other NF$\kappa \mathrm{B}$ subunits in MUT-TP53 diffuse large B-cell lymphoma. Differential activities and function of different $\mathrm{NF}-\kappa \mathrm{B}$ dimers formed in germinal center B-cell-like diffuse large B-cell lymphoma and activated B-cell-like diffuse large B-cell lymphoma and in WT-TP53 and MUT-TP53 diffuse large B-cell lymphoma may contribute to the different prognostic impact observed in these diffuse large B-cell lymphoma subsets. No other known unfavorable bio-

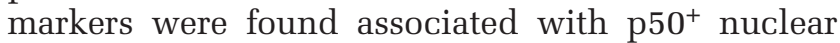
expression. In contrast, the ${\mathrm{p} 50^{+}}^{+}$patient group had 
lower Ki-67 scores and a lower frequency of BCL2 translocations, and less often had Myc, PI3K, p-AKT CXCR4, and FOXP1 overexpression (which were all oncogenic mechanisms in diffuse large B-cell lymphoma by previous studies) in the WT-TP53 diffuse large B-cell lymphoma and/or activated B-cell-like diffuse large B-cell lymphoma subcohorts. These 'mutual exclusive'-like negative correlations and the

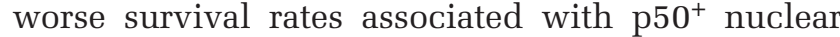
expression in WT-TP53 diffuse large B-cell lymphoma may suggest that p50 activation is an important and unique mechanism for R-CHOP resistance in diffuse large B-cell lymphoma.

In addition to the negative correlations with proliferative/antiapoptotic biomarkers such as Myc/ Bcl-2, PI3K/AKT, and CXCR4, the p50 ${ }^{+}$gene expression signatures showed that several proapoptotic genes were upregulated in $\mathrm{p} 50^{+}$patients, such as $C A S P 4, X A F 1, D A P K 1$, and EPB41L3, suggesting that the adverse prognostic impact of p50 activation in WT-TP53 diffuse large B-cell lymphoma is not the result of promoting tumor growth and survival, the common functions of $\mathrm{NF}-\kappa \mathrm{B}$. Remarkably, a large numbers of immune-related genes were upregulated in ${\mathrm{p} 50^{+}}$patients, including a few having inhibitory function. Previous studies have reported that p50 has both negative and positive roles in regulating inflammatory responses, with a possible explanation being that p50 NF- $\kappa$ B dimers can function as both transcriptional activators and repressors. ${ }^{6,7}$ The 'anti-inflammatory brake'-like function of p50 (ref. 6) may be relevant to the worse prognosis associated with p50 activation in diffuse large B-cell lymphoma. Most notably, HAVCR2, which encodes the inhibitory immune checkpoint TIM-3, was upregulated in both germinal center B-cell-like and activated B-cell-like subtypes of p50 ${ }^{+}$diffuse large B-cell lymphoma. TIM-3 is a receptor expressed on activated Th1 cells; binding of TIM-3 by its ligand galectin-9 leads to Th1 cell death and immune tolerance. TIM-3 has gained attention as a new immune checkpoint target. It has been reported that TIM-3 confers resistance to anti-PD-1 therapy. ${ }^{29,45,46}$ In addition, upregulation of CD163, SERPING1, IL18BP, LILRA2, LILRA6, and LILRB2/4/3 might suggest suppression of adaptive and innate immune responses conferring poorer outcome in ${\mathrm{p} 50^{+}}^{+}$diffuse large B-cell lymphoma patients. Targeting these immunosuppressive mechanisms may restore the antitumor effects of immune responses that have been activated in ${\mathrm{p} 50^{+}}^{+}$ diffuse large B-cell lymphoma patients.

Oppositely, p50 ${ }^{+}$status in the MUT-TP53 germinal center B-cell-like diffuse large B-cell lymphoma subgroup correlated with significantly better survival rates. This favorable effect could be contributed by the decreased MUT-p53 (which often had oncogenic gain of function ${ }^{23}$ ), Bcl-2, and Myc expression in $\mathrm{p} 50^{+}$patients, activated immune responses as suggested by the gene expression signatures, and other unknown factors not identified in this study. The correlation of decreased MUT-p53 expression in p50 ${ }^{+}$patients was not due to regulation at the transcriptional level. The causative link for this negative correlation in diffuse large B-cell lymphoma patients with MUT-TP53, whether it determines the favorable prognosis associated with p50 activation, and whether p50 had opposite transcriptional functions in the presence of WT-p53 and MUT-p53 towards immune and inflammatory genes, needs be validated by further studies.

The ${\mathrm{p} 50^{+}}^{+}$gene expression signatures obtained in this study also revealed several upstream signaling pathways that may lead to the activation of p50 and its associated $\mathrm{NF}-\kappa \mathrm{B}$ subunits in diffuse large B-cell lymphoma. Canonical activation was suggested by upregulation of $I K B K B / I K K 2$ (in activated B-cell-like diffuse large B-cell lymphoma), TLRs, and tumor necrosis factor (TNF) ligands/receptors in ${\mathrm{p} 50^{+}}^{+}$ patients. Comparably, BCR signaling seemed not significant for p50 activation in diffuse large B-cell lymphoma especially in germinal center B-cell-like diffuse large B-cell lymphoma, suggesting that BCR inhibitors may not be effective for ${\mathrm{p} 50^{+}}^{+}$germinal center B-cell-like diffuse large B-cell lymphoma. Activation of noncanonical NF- $\kappa$ B pathway was also suggested by significantly upregulated $B A F F$ in all p50 ${ }^{+}$patients and $B A F F R$ in the $5^{+}$activated B-celllike diffuse large B-cell lymphoma subgroup. ${ }^{47}$

In summary, in a large number of patients with diffuse large B-cell lymphoma, p50 ${ }^{+}$nuclear expression is an independent prognostic factor for significantly poorer survival in patients with WT-TP53 diffuse large B-cell lymphoma, although it correlates with decreased Myc/Bcl-2/AKT expression. p50 represents an essential $\mathrm{NF}-\kappa \mathrm{B}$ subunit activated in activated B-cell-like diffuse large B-cell lymphoma that correlates with $\mathrm{R}-\mathrm{CHOP}$ resistance in the absence of TP53 mutations and Myc/Bcl-2/AKT hyperactivation. Gene expression profiling analysis suggests that immunosuppressive mechanisms, but not antiapoptosis and proliferation, underscore the worse prognosis associated with p50 activation, and provides important information for further functional and therapeutic studies.

\section{Acknowledgments}

This study was supported by grants from the National Cancer Institute and the National Institutes of Health (R01CA138688, R01CA187415, and 1RC1CA146299 to KHY). KHY is supported by The University of Texas MD Anderson Cancer Center Institutional Research Grant Award, an MD Anderson Lymphoma Specialized Programs of Research Excellence (SPORE) Research Development Program Award, and an MD Anderson Myeloma SPORE Research Developmental Program Award. QC was supported by National Natural Science Foundation of China (No. 81672686, No. 81372883, and No. 81001052), Natural Science Foundation of Guangdong Province, China (2015A030313020), Science 
and Technology Planning Project of Guangdong Province, China (2011B031800222), Young Talents Key Project of Sun Yat-sen University (2015ykzd13). The study is partially supported by P50CA136411 and P50CA142509, the MD Anderson Cancer Center Support Grant CA016672, and the Sister Institution Network Fund of MD Anderson Cancer Center (to KHY and QC).

\section{Disclosure/conflict of interest}

KHY receives research support from Roche Molecular System, Gilead Sciences Pharmaceutical, Seattle Genetics, Dai Sanyo Pharmaceutical, Adaptive Biotechnology, Incyte Pharmaceutical, and HTG Molecular Diagnostics. The remaining authors declare no conflict of interest.

\section{References}

1 Chen CD, Sawyers CL. NF-kappaB activates prostatespecific antigen expression and is upregulated in androgen-independent prostate cancer. Mol Cell Biol 2002;22:2862-2870.

2 Basseres DS, Baldwin AS. Nuclear factor-kappaB and inhibitor of kappaB kinase pathways in oncogenic initiation and progression. Oncogene 2006;25: 6817-6830.

3 Siebenlist U, Franzoso G, Brown K. Structure, regulation and function of NF-kappaB. Annu Rev Cell Biol 1994;10:405-455.

4 Mathas S, Jöhrens K, Joos S, et al. Elevated NF-kappaB p50 complex formation and Bcl-3 expression in classical Hodgkin, anaplastic large-cell, and other peripheral T-cell lymphomas. Blood 2005;106:4287-4293.

5 Staudt LM. Oncogenic activation of NF-kappaB. Cold Spring Harb Perspect Biol 2010;2:a000109.

6 Pereira SG, Oakley F. Nuclear factor-kappaB1: regulation and function. Int J Biochem Cell Biol 2008;40: 1425-1430.

7 Beinke S, Ley SC. Functions of NF-kappaB1 and NFkappaB2 in immune cell biology. Biochem J 2004;382: 393-409.

$8 \mathrm{Yu}$ Y, Wan Y, Huang C. The biological functions of NFkappaB1 (p50) and its potential as an anti-cancer target. Curr Cancer Drug Targets 2009;9:566-571.

9 Hoesel B, Schmid JA. The complexity of NF-kappaB signaling in inflammation and cancer. Mol Cancer 2013;12:86.

10 Chen Y, Lu R, Zheng H, et al. The NFKB1 polymorphism (rs4648068) is associated with the cell proliferation and motility in gastric cancer. BMC Gastroenterol 2015;15:21.

11 Guzman ML, Neering SJ, Upchurch D, et al. Nuclear factor-kappaB is constitutively activated in primitive human acute myelogenous leukemia cells. Blood 2001;98:2301-2307.

12 Meylan E, Dooley AL, Feldser DM, et al. Requirement for NF-kappa B signalling in a mouse model of lung adenocarcinoma. Nature 2009;462:104-107.

13 Muller PAJ, Vousden KH, Norman JC. p53 and its mutants in tumor cell migration and invasion. J Cell Biol 2011;192:209-218.
14 Webster GA, Perkins ND. Transcriptional cross talk between NF-kappB and p53. Mol Cell Biol 1999;19: 3485-3495.

$15 \mathrm{Gu} \mathrm{L}$, Zhu N, Findley HW, et al. Identification and characterization of the IKK $\alpha$ promoter positive and negative regulation by ETS-1 and p53, respectively. J Biol Chem 2004;279:52141-52149.

16 Rocha S, Martin AM, Meek DW, et al. p53 represses cyclin D1 transcription through down regulation of Bcl3 and inducing increased association of the p52 NF-кB subunit with histone deacetylase 1. Mol Cell Biol 2003;23:4713-4727.

17 Cooks T, Pateras IS, Tarcic O, et al. Mutant p53 prolongs $\mathrm{NF}-\kappa \mathrm{B}$ activation and promotes chronic inflammation and inflammation-associated colorectal cancer. Cancer Cell 2013;23:634-646.

18 Gasparini C, Celeghini C, Monasta L, et al. NF-кB pathways in hematological malignancies. Cell Mol Life Sci 2014;71:2083-2102.

$19 \mathrm{Yu}$ Y, Zhang D, Huang H, et al. NF-kB1 p50 promotes p53 protein translation through miR-190 downregulation of PHLPP1. Oncogene 2014;33:996-1005.

20 Davis RE, Brown KD, Siebenlist U, et al. Constitutive nuclear factor kappB activity is required for survival of activated B cell-like diffuse large B cell lymphoma cells. J Exp Med 2001;194:1861-1874.

21 Ok CY, Xu-Monette ZY, et al. Evaluation of NF-kB subunit expression and signaling pathway activation demonstrates that p52 expression confers better outcome in germinal center B-cell-like diffuse large B-cell lymphoma in association with CD30 and BCL2 functions. Mod Pathol 2015;28:1202-1213.

22 Visco C, Li Y, Xu-Monette ZY, et al. Comprehensive gene expression profiling and immunohistochemical studies support application of immunophenotypic algorithm for molecular subtype classification in diffuse large B-cell lymphoma: a report from the International DLBCL Rituximab-CHOP Consortium Program Study. Leukemia 2012;26:2103-2113.

23 Xu-Monette ZY, Wu L, Visco C, et al. Mutational profile and prognostic significance of TP53 in diffuse large B-cell lymphoma patients treated with R-CHOP: report from an International DLBCL Rituximab-CHOP Consortium Program Study. Blood 2012;120: 3986-3996.

24 Tzankov A, Xu-Monette ZY, Gerhard M, et al. Rearrangements of MYC gene facilitate risk stratification in diffuse large B-cell lymphoma patients treated with rituximab-CHOP. Mod Pathol 2014;27:958-971.

25 Curry CV, Ewton AA, Olsen RJ, et al. Prognostic impact of C-REL expression in diffuse large B-cell lymphoma. J Hematop 2009;2:20-26.

26 Chen J, Xu-Monette ZY, Deng L, et al. Dysregulated CXCR4 expression promotes lymphoma cell survival and independently predicts disease progression in germinal center B-cell-like diffuse large B-cell lymphoma. Oncotarget 2015;6:5597-5614.

$27 \mathrm{Hu} \mathrm{S}$, Xu-Monette ZY, Tzankov A, et al. MYC/BCL2 protein coexpression contributes to the inferior survival of activated B-cell subtype of diffuse large B-cell lymphoma and demonstrates high-risk gene expression signatures: a report from The International DLBCL Rituximab-CHOP Consortium Program. Blood 2013; 121:4021-4031.

28 Xu-Monette ZY, Dabaja BS, Wang X, et al. Clinical features, tumor biology, and prognosis associated with MYC rearrangement and Myc overexpression in diffuse 
large B-cell lymphoma patients treated with rituximabCHOP. Mod Pathol 2015;28:1555-1573.

29 Ngiow SF, Teng MW, Smyth MJ. Prospects for TIM3targeted antitumor immunotherapy. Cancer Res 2011; 71:6567-6571.

30 Komohara Y, Niino D, Saito Y, et al. Clinical significance of CD163(+) tumor-associated macrophages in patients with adult T-cell leukemia/lymphoma. Cancer Sci 2013;104:945-951.

31 Murray-Rust TA, Kerr FK, Thomas AR, et al. Modulation of the proteolytic activity of the complement protease C1s by polyanions: implications for polyanion-mediated acceleration of interaction between C1s and SERPING1. Biochem J 2009;422:295-303.

32 Brown DP, Jones DC, Anderson KJ, et al. The inhibitory receptor LILRB4 (ILT3) modulates antigen presenting cell phenotype and, along with LILRB2 (ILT4), is upregulated in response to Salmonella infection. BMC Immunol 2009;10:56.

33 Kim JR, Horton NC, Mathew SO, et al. CS1 (SLAMF7) inhibits production of proinflammatory cytokines by activated monocytes. Inflamm Res 2013;62:765-772.

34 Rollinger-Holzinger I, Eibl B, Pauly M, et al. LST1: a gene with extensive alternative splicing and immunomodulatory function. J Immunol 2000;164: 3169-3176.

35 Murata T, Sato T, Kamoda $\mathrm{T}$, et al. Differential susceptibility to hydrogen sulfide-induced apoptosis between PHLDA1-overexpressing oral cancer cell lines and oral keratinocytes: role of PHLDA1 as an apoptosis suppressor. Exp Cell Res 2014;320:247-257.

36 Zou B, Chim CS, Pang R, et al. XIAP-associated factor 1 (XAF1), a novel target of p53, enhances p53-mediated apoptosis via post-translational modification. Mol Carcinog 2012;51:422-432.
37 Jiang W, Newsham IF. The tumor suppressor DAL-1/4.1B and protein methylation cooperate in inducing apoptosis in MCF-7 breast cancer cells. Mol Cancer 2006;5:4.

38 van Keimpema M, Gruneberg LJ, Mokry M, et al. FOXP1 directly represses transcription of proapoptotic genes and cooperates with NF-kappaB to promote survival of human B cells. Blood 2014;124: 3431-3440.

39 Rickert RC, Jellusova J, Miletic AV. Signaling by the tumor necrosis factor receptor superfamily in B-cell biology and disease. Immunol Rev 2011;244:115-133.

40 Sun SC. Non-canonical NF-kappaB signaling pathway. Cell Res 2011;21:71-85.

41 Kawai T, Akira S. Signaling to NF-kappaB by Toll-like receptors. Trends Mol Med 2007;13:460-469.

42 Kim SH, Han SY, Azam T, et al. Interleukin-32: a cytokine and inducer of TNFalpha. Immunity 2005;22: 131-142.

43 Novick D, Kim SH, Fantuzzi G, et al. Interleukin-18 binding protein: a novel modulator of the Th1 cytokine response. Immunity 1999;10:127-136.

$44 \mathrm{Li} \mathrm{L}, \mathrm{Xu}-\mathrm{Monette} \mathrm{ZY,} \mathrm{Ok} \mathrm{CY,} \mathrm{et} \mathrm{al.} \mathrm{Prognostic} \mathrm{impact} \mathrm{of}$ c-Rel nuclear expression and REL amplification and crosstalk between c-Rel and the p53 pathway in diffuse large B-cell lymphoma. Oncotarget 2015;6:23157-23180.

45 Ge RT, Zeng L, Mo LH, et al. Interaction of TIM4 and TIM3 induces $\mathrm{T}$ helper 1 cell apoptosis. Immunol Res 2016;64:470-475.

46 Romero D. Immunotherapy: PD-1 says goodbye, TIM-3 says hello. Nat Rev Clin Oncol 2016;13:202-203.

$47 \mathrm{Yu}$ L, Li L, Medeiros LJ, et al. NF-кB signaling pathway and its potential as a target for therapy in lymphoid neoplasms. Blood Rev; e-pub ahead of print 16 October 2013; doi: 10.1016/j.blre.2016.10.001. 